\title{
Interannual variation patterns of total ozone and lower stratospheric temperature in observations and model simulations
}

\author{
W. Steinbrecht ${ }^{1}$, B. Haßler ${ }^{1}$, C. Brühl ${ }^{2}$, M. Dameris ${ }^{3}$, M. A. Giorgetta ${ }^{4}$, V. Grewe ${ }^{3}$, E. Manzini ${ }^{5}$, S. Matthes ${ }^{3}$, \\ C. Schnadt ${ }^{3, *}$, B. Steil ${ }^{2}$, and P. Winkler ${ }^{1}$ \\ ${ }^{1}$ Meteorologisches Observatorium Hohenpeißenberg, Deutscher Wetterdienst, Hohenpeißenberg, Germany \\ ${ }^{2}$ Chemie der Atmosphäre, Max Planck Institut für Chemie, Mainz, Germany \\ ${ }^{3}$ Institut für Physik der Atmosphäre, Deutsches Zentrum für Luft und Raumfahrt, Oberpfaffenhofen, Germany \\ ${ }^{4}$ Atmosphäre im Erdsystem, Max Planck Institut für Meteorologie, Hamburg, Germany \\ ${ }^{5}$ Istituto Nazionale di Geofisica e Vulcanologia, Bologna, Italy \\ *now at: Institut für Atmosphäre und Klima, Eidgenössische Technische Hochschule, Zürich, Switzerland
}

Received: 5 August 2005 - Published in Atmos. Chem. Phys. Discuss.: 26 September 2005

Revised: 20 December 2005 - Accepted: 30 December 2005 - Published: 6 February 2006

\begin{abstract}
We report results from a multiple linear regression analysis of long-term total ozone observations (1979 to 2000, by TOMS/SBUV), of temperature reanalyses (1958 to 2000, NCEP), and of two chemistry-climate model simulations (1960 to 1999, by ECHAM4.L39(DLR)/CHEM (=E39/C), and MAECHAM4-CHEM). The model runs are transient experiments, where observed sea surface temperatures, increasing source gas concentrations $\left(\mathrm{CO}_{2}, C F C \mathrm{~s}\right.$, $\mathrm{CH}_{4}, \mathrm{~N}_{2} \mathrm{O}, \mathrm{NO}_{\mathrm{x}}$ ), 11-year solar cycle, volcanic aerosols and the quasi-biennial oscillation (QBO) are all accounted for. MAECHAM4-CHEM covers the atmosphere from the surface up to $0.01 \mathrm{hPa}(\approx 80 \mathrm{~km})$. For a proper representation of middle atmosphere (MA) dynamics, it includes a parametrization for momentum deposition by dissipating gravity wave spectra. E39/C, on the other hand, has its top layer centered at $10 \mathrm{hPa}(\approx 30 \mathrm{~km})$. It is targeted on processes near the tropopause, and has more levels in this region. Despite some problems, both models generally reproduce the observed amplitudes and much of the observed lowlatitude patterns of the various modes of interannual variability in total ozone and lower stratospheric temperature. In most aspects MAECHAM4-CHEM performs slightly better than E39/C. MAECHAM4-CHEM overestimates the longterm decline of total ozone, whereas E39/C underestimates the decline over Antarctica and at northern mid-latitudes. The true long-term decline in winter and spring above the
\end{abstract}

Correspondence to: W. Steinbrecht

(wolfgang.steinbrecht@dwd.de)
Arctic may be underestimated by a lack of TOMS/SBUV observations in winter, particularly in the cold 1990s. Main contributions to the observed interannual variations of total ozone and lower stratospheric temperature at $50 \mathrm{hPa}$ come from a linear trend (up to -10 DU/decade at high northern latitudes, up to $-40 \mathrm{DU} /$ decade at high southern latitudes, and around $-0.7 \mathrm{~K} / \mathrm{decade}$ over much of the globe), from the intensity of the polar vortices (more than $40 \mathrm{DU}$, or $8 \mathrm{~K}$ peak to peak), the QBO (up to $20 \mathrm{DU}$, or $2 \mathrm{~K}$ peak to peak), and from tropospheric weather (up to $20 \mathrm{DU}$, or $2 \mathrm{~K}$ peak to peak). Smaller variations are related to the 11-year solar cycle (generally less than $15 \mathrm{DU}$, or $1 \mathrm{~K}$ ), or to ENSO (up to $10 \mathrm{DU}$, or $1 \mathrm{~K}$ ). These observed variations are replicated well in the simulations. Volcanic eruptions have resulted in sporadic changes (up to $-30 \mathrm{DU}$, or $+3 \mathrm{~K}$ ). At low latitudes, patterns are zonally symmetric. At higher latitudes, however, strong, zonally non-symmetric signals are found close to the Aleutian Islands or south of Australia. Such asymmetric features appear in the model runs as well, but often at different longitudes than in the observations. The results point to a key role of the zonally asymmetric Aleutian (or Australian) stratospheric anti-cyclones for interannual variations at high-latitudes, and for coupling between polar vortex strength, QBO, 11-year solar cycle and ENSO. 


\section{Introduction}

For many years, general circulation models (GCMs) have been major tools for atmospheric prediction. For weather forecasting, their time scales range from hours to days, for climate studies from years to decades (IPCC, 2001). On these longer time scales, decadal changes in radiatively active trace gases like $\mathrm{H}_{2} \mathrm{O}, \mathrm{CO}_{2}, \mathrm{O}_{3}, C F C \mathrm{~s}, \mathrm{~N}_{2} \mathrm{O}$, and $\mathrm{NO}_{\mathrm{x}}$ are important, particularly in the stratosphere (IPCC, 2001; WMO, 2003; Shine et al., 2003). For the investigation of stratospheric ozone depletion and its connection to climate change (WMO, 2003), many recent "chemistry-climate models" include a representation of atmospheric trace gases, their sources, sinks, and chemical reactions relevant for the stratosphere (Austin et al., 2003). Trace gases are transported throughout the model atmosphere. Their distributions change in space and time due to transport processes and photo-chemical reactions. Trace gas abundances are fed back into the radiation code of the model. Thus, changes in trace gases interactively couple back into dynamics and transport. This is essential for investigating connections between stratospheric ozone changes and climate change.

Climatologies and trends from stratospheric "chemistryclimate models" are realistic and have been validated (Hein et al., 2001; Austin et al., 2003; Manzini et al., 2003; Shine et al., 2003; Steil et al., 2003). The purpose of this study is to extend this climatological validation to the comparison of interannual variation patterns. In this sense, we "validate" two recent 40 year transient simulations by ECHAM4.L39(DLR)/CHEM, called E39/C hereafter (Dameris et al., 2005), and MAECHAM4-CHEM (Steil et al., 2003; Manzini et al., 2003). These simulations try to account for nearly all important sources of variance in the real atmosphere between 1960 and 2000. We compare typical modes and patterns of the interannual variations of total ozone and temperature from these two model simulations, with those actually observed.

We follow the approach of Steinbrecht et al. (2003), which was based on a multiple linear regression analysis of near global long-term total ozone observations from satellitebased Total Ozone Monitoring Spectrometer (TOMS) and Solar Backscatter Ultra Violet (SBUV) instruments (Stolarski and Hollandsworth, 2003), and of temperature fields from NCEP reanalyses (Kistler et al., 2001). This provides global maps of interannual variation patterns of total ozone and lower stratospheric temperature (e.g. $50 \mathrm{hPa}$, or $\approx 22 \mathrm{~km}$ ), correlated with the quasi-biennial oscillation of Equatorial zonal wind (QBO), with the 11-year cycle of solar activity, or with other influences. For observations and reanalyses, the results are the same as in Steinbrecht et al. (2003). The same methodology is now applied to simulated total ozone and temperature fields from the two 40-year long model runs, and observed and modelled interannual variation patterns can be compared.

\section{Data and method}

\subsection{Simulations and observations}

The simulations were performed with two models derived from the European Center HAMburg version 4 (Roeckner et al., 1996), and the MA-ECHAM4 (Manzini et al., 1997) general circulation models: ECHAM4.L39(DLR)/CHEM, called E39/C hereafter, and MAECHAM4-CHEM. Both are based on full coupling of the general circulation (GCM) model with the chemistry model CHEM (Steil et al., 1998). While the general circulation (GCM) part accounts for the meteorological processes, CHEM simulates the photochemistry relevant to stratospheric ozone, including heterogeneous chemistry. Trace gas concentrations from CHEM are fed back into the radiative scheme of the GCMs (Steil et al., 2003). For both simulations, the horizontal resolution used in the GCMs was the T30 truncation, and the mesh size for $\mathrm{CHEM}$ was $3.75^{\circ} \times 3.75^{\circ}$. In E39/C, 39 vertical model levels reach from the surface up to $10 \mathrm{hPa}(30 \mathrm{~km})$ (Dameris et al., 2005), whereas in MAECHAM4-CHEM 39 model levels reach from the surface up to $0.01 \mathrm{hPa}(80 \mathrm{~km})$ (Steil et al., 2003; Manzini et al., 2003). With more levels near the tropopause, E39/C is targeted more on processes around the tropopause (Grewe et al., 2001; Schnadt et al., 2002; Schnadt and Dameris, 2003). MAECHAM4-CHEM, on the other hand, is a full troposphere-stratosphere-mesosphere model (Manzini et al., 1997; Manzini et al., 2003). It includes better radiation and dissipation processes, especially momentum deposition by dissipating gravity wave spectra, which is parameterized in MAECHAM4-CHEM (Manzini and McFarlane, 1998), but not in E39/C. The two models also differ in their trace gas transport scheme: E39/C uses a semiLagrange method following Williamson and Rasch (1989), whereas MAECHAM4-CHEM uses the less diffusive SPITFIRE scheme (Rasch and Lawrence, 1998).

With both models, a simulation covering the 1960 to 1999 time period was carried out, with the same "transient" boundary conditions, i.e. realistically increasing chlorine and greenhouse gas concentrations $\left(C F C \mathrm{~s}, \mathrm{CO}_{2}, \mathrm{~N}_{2} \mathrm{O}, \mathrm{CH}_{4}\right.$, and $\mathrm{NO}_{\mathrm{x}}$; WMO, 2003), and observed variations in sea surface temperatures and ice-coverage (Rayner et al., 2003). Both simulations also included a nudged QBO (Giorgetta and Bengtsson, 1999), volcanic aerosol effects from the major eruptions in 1963, 1982, and 1991 (Timmreck et al., 2004), and spectral solar irradiation changes following the 11-year solar cycle. For the latter, $10.7 \mathrm{~cm}$ solar radio flux was converted to UV changes, as described in Lean et al. (1997). See also Tourpali et al. (2003). Details for the E39/C transient simulation, and the boundary conditions, are given in Dameris et al. (2005). The same boundary conditions were used for the MAECHAM4-CHEM run.

The subsequent analysis is based on gridded monthly mean data. For TOMS/SBUV we used the gridded version 7 data set on a $5^{\circ} \times 10^{\circ}$ latitude by longitude grid from Stolarski 
and Hollandsworth (2003), over the period from November 1978 to December 2000. Since TOMS and SBUV need sunlight for their measurements, no data are available in the polar regions in winter. NCEP reanalysis data are available throughout the year, on a $2.5^{\circ} \times 2.5^{\circ}$ grid (Kistler et al., 2001). Here we use NCEP data from January 1958 to December 2000, regridded to the TOMS/SBUV grid. The E39/C and MAECHAM4-CHEM monthly means are on a $3.75^{\circ} \times 3.75^{\circ}$ grid, and cover the period from January 1960 to December 1999. For the analysis we use total ozone anomalies $\Delta \mathrm{O}_{3}$, and temperature anomalies $\Delta T$ at 50 and $400 \mathrm{hPa}$. Anomalies were derived by subtracting the climatological long-term monthly mean for the appropriate month of the year and for each grid-cell from the actual monthly mean at each grid-cell.

\subsection{Zonal mean anomalies}

The long-term evolution of zonal mean anomalies for observations and model simulations, for total column ozone, and for lower stratospheric temperature at $50 \mathrm{hPa}(\approx 22 \mathrm{~km})$ is given in Fig. 1. The largest interannual variations in the stratosphere are found at high northern, and high southern latitudes. They are seasonally synchronized, and occur in winter and spring. Variations in the tropical and subtropical stratosphere are smaller, more regular, and less synchronized with season. Both model simulations give a similar picture to the observations and reanalyses.

However, the substantially lower $50 \mathrm{hPa}$ temperatures before 1979 in the area south of $30^{\circ} \mathrm{S}$ in the NCEP reanalyses (blue colours in the left panels of Fig. 1) are not seen in the simulations. Before the introduction of global satellite observations in 1979, the observational basis was quite sparse in the Southern Hemisphere, particularly in the stratosphere. After 1979, this situation changed dramatically Kistler et al. (2001). This step is quite apparent in the NCEP reanalyses in Fig. 1. Other, minor changes may have occured at other times. We have to be very careful, therefore, especially when using NCEP reanalysis data from the Southern Hemisphere before 1979. However, with the exception of trends, most of our results from the NCEP reanalysis were very similar, whether obtained for the 1979 to 2000 period, or for the 1958 to 2000 period. Also the results for $50 \mathrm{hPa}$ temperature are usually supported by similar results for total ozone, which are derived from the homogenized and more consistent TOMS/SBUV data set. Agreement with the perse consistent model simulations can also give support for our $50 \mathrm{hPa}$ temperature results. Nevertheless, potential problems with NCEP data consistency have to be kept in mind.

A long term decline of total column ozone can be seen in the top panels of Fig. 1, by the change from red to blue colours. This decline is most pronounced at high southern latitudes, where the "Antarctic ozone hole" has been occuring since 1984. It is also large at northern latitudes, particularly in the 1990s. Compared to TOMS or the E39/C simulation, the ozone decline is much more pronounced in the MAECHAM4-CHEM simulation. It is important to note, however, that no TOMS/SBUV observations are available in polar winters, especially in many of the Arctic winters with large ozone depletion in the 1990s. It is, therefore, quite likely that the true total ozone trend above the Arctic is larger than observed by the combined TOMS/SBUV data-set.

Along with the ozone decline, the stratosphere, e.g. at $50 \mathrm{hPa}$, has been getting colder. This cooling is most visible by the blue colours in the tropics after 1993. At high latitudes, interannual variations are very large, and Fig. 1 gives no clear indication for a cooling trend. As mentioned, the step in NCEP temperatures around 1979 has to be treated with suspicion and makes this data set problematic for the derivation of trends starting before 1979. Trends are discussed in Sect. 3.3.

The QBO, indicated by the black line near the Equator, shows a very clear influence on total ozone and $50 \mathrm{hPa}$ temperature in tropics and sub-tropics. This is seen in observations/reanalysis and in both simulations. Phase changes of the QBO signal appear around $15^{\circ}$ latitude, and possibly also around $50^{\circ}$ to $60^{\circ}$ latitude for $50 \mathrm{hPa}$ temperature. The QBO signal is discussed in Sect. 3.4. While the QBO signal is, in general, quite visible, effects of the 11-year solar cycle (indicated by the black line near $90^{\circ} \mathrm{N}$ ) are much less obvious, at least for the altitude levels shown in Fig. 1. One might see a tendency for higher total ozone and higher $50 \mathrm{hPa}$ temperatures during solar maxima. See Sect. 3.5 for solar cycle effects.

Very pronounced warmings appear in $50 \mathrm{hPa}$ temperature after the 3 major volcanic eruptions of 1963, 1982 and 1991. These warmings are generally too large in the simulations compared to the reanalysis. This is discussed in Sect. 3.6.

\subsection{Multiple linear regression}

Figure 1 gives qualitative indication of different factors contributing to interannual and long-term variations of total ozone and temperature. In the following, we try to quantify these. From general knowledge about main influences on total ozone or lower stratospheric temperature (e.g. WMO, 2003), we assume a priori that only certain main variations are important. Each is represented by a "predictor" time series, e.g. the QBO by Equatorial zonal wind anomalies, the 11 -year solar cycle by solar radio flux at $10.7 \mathrm{~cm}$, the El Niño/Southern Oscillation by the Southern Oscillation Index, and so on. An attribution to a few statistically significant main factors can be done by multiple linear regression. For each individual latitude longitude grid-cell, total ozone column anomalies $\Delta \mathrm{O}_{3}$, or temperature anomalies $\Delta T$, are described as a sum of predictor terms:

$$
\begin{aligned}
\Delta Y= & c_{T R} T R+c_{F S} F S+c_{A} A+c_{T(400)} T(400) \\
& +c_{Q B O(10)} Q B O(10)+c_{Q B O(30)} Q B O(30) \\
& +c_{u(60 N)} u(60 N)+c_{u(60 S)} u(60 S) \\
& +c_{E N S O} E N S O+\text { residual }
\end{aligned}
$$




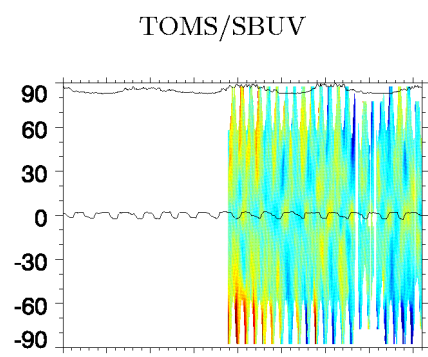

$\begin{array}{lllllllll}60 & 65 & 70 & 75 & 80 & 85 & 90 & 95 & 00\end{array}$ NCEP

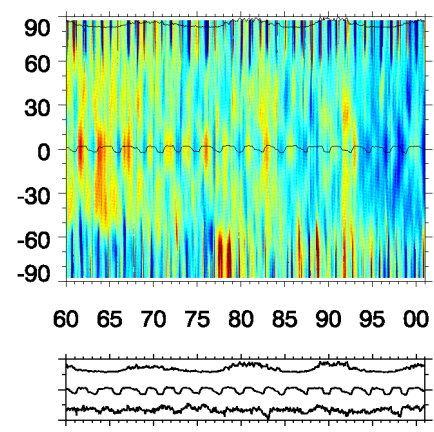

$\begin{array}{lllllllll}60 & 65 & 70 & 75 & 80 & 85 & 90 & 95 & 00\end{array}$

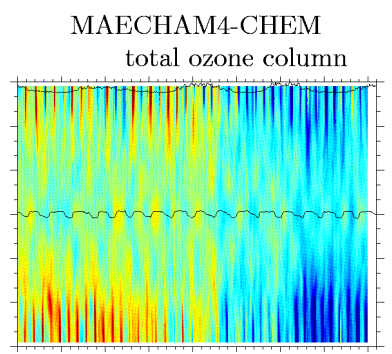

$\begin{array}{lllllllll}60 & 65 & 70 & 75 & 80 & 85 & 90 & 95 & 00\end{array}$ MAECHAM4-CHEM temperature at $50 \mathrm{hPa}$
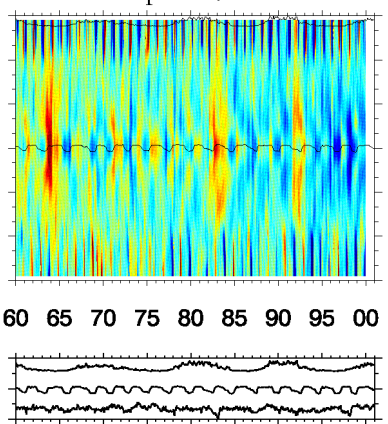

$\begin{array}{lllllllll}60 & 65 & 70 & 75 & 80 & 85 & 90 & 95 & 00\end{array}$
$\mathrm{E} 39 / \mathrm{C}$

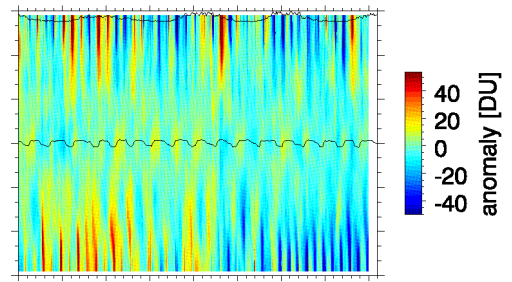

$\begin{array}{lllllllll}60 & 65 & 70 & 75 & 80 & 85 & 90 & 95 & 00\end{array}$ $\mathrm{E} 39 / \mathrm{C}$

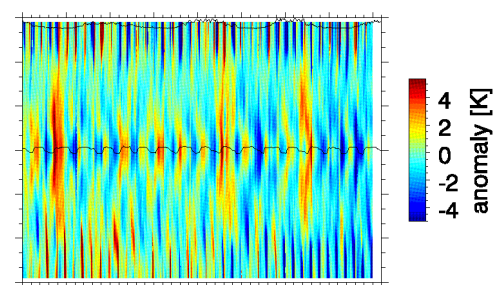

$\begin{array}{lllllllll}60 & 65 & 70 & 75 & 80 & 85 & 90 & 95 & 00\end{array}$

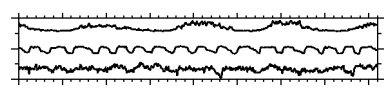

$\begin{array}{lllllllll}60 & 65 & 70 & 75 & 80 & 85 & 90 & 95 & 00\end{array}$

Fig. 1. Zonal anomaly time series for latitudes from $90^{\circ} \mathrm{S}$ to $90^{\circ} \mathrm{N}$ (y-axes), and for the period 1960 to 2000 (x-axes). Anomalies are colourcoded with yellow and red colours corresponding to positive anomalies, and cyan and blue colours corresponding to negative anomalies. Top row shows total column ozone anomalies, bottom row shows temperature anomalies at $50 \mathrm{hPa}(\approx 22 \mathrm{~km})$. The left column gives results for TOMS/SBUV observations, not available before 1979, and for NCEP reanalysis, the middle column for the transient simulation with MAECHAM4-CHEM, and the right column for the transient simulation with ECHAM4.L39(DLR)/CHEM (=E39/C). The black line near the top of each plot gives $10.7 \mathrm{~cm}$ solar-flux as an indicator for the 11-year solar cycle. The black line near the Equator gives equatorial zonal wind anomalies at $40 \mathrm{hPa}$ as a proxy for the QBO. At the very bottom, these two index time series are repeated again, along with the Southern Oscillation Index, which is negative during El Niño warm events and positive during La Niña cold events.

From a given time series $\Delta Y$ at an individual grid cell, and from given influences, or "predictor" time series $X$, the coefficients $c_{X}$ can be determined by a multiple linear least squares fit. The residual is, in general, an auto-correlated noise time series. Here we neglect the noise autocorrelation, which is usually smaller than 0.5 in the tropics, and smaller than 0.3 outside of the tropics. The statistical significance level of our results might, therefore, be overestimated, especially in the tropics. For our purposes we use the predictor time series $T R$ for a linear trend, $10.7 \mathrm{~cm}$ solar radio flux $F S$ for the 11-year solar cycle, stratospheric aerosol optical depth $A$ for stratospheric aerosol loading, $T(400)$ for tropospheric temperature (anomalies) at $400 \mathrm{hPa}$, Equatorial zonal wind anomalies at 10 and $30 \mathrm{hPa}, Q B O(10)$ and $Q B O(30)$, for the quasi-biennial oscillation, zonal wind anomalies at $60^{\circ}$ latitude, $50 \mathrm{hPa}, u(60 \mathrm{~N})$ and $u(60 \mathrm{~S})$, as proxies for Polar Vortex strength, and the Southern Oscillation Index for the El Niño/Southern Oscillation (ENSO) variation. See Steinbrecht et al. (2003) for details.

The regression according to Eq. (1) is carried out separately for each grid cell, and separately for the four seasons, northern winter (December, January, February), north- ern spring (March, April, May), northern summer (June, July, August), and northern fall (September, October, December). For each grid cell, and for the four seasons, the different terms $c_{X} X$ then describe ozone, or temperature variations correlated with predictor $X$. As in Steinbrecht et al. (2003), a stepwise regression approach is used. The most important predictor is added first. Other predictors are tested and added later, if they are statistically significant at the, possibly overestimated, $90 \%$ confidence level of a partial $\mathrm{F}$ test. At each step, insignificant predictors are dropped. In the end, only the most significant predictors remain in the Equation.

With the notable exception of $T(400)$ and ENSO in the tropics, the predictor time series are sufficiently orthogonal (Steinbrecht et al., 2003). For nearly all other predictors, the correlation with other predictors is less than \pm 0.2 . The exclusion of the less significant predictors further reduces problems by allowing only one of two more correlated predictors. In several tests, reducing the set of predictors gave very similar results for the remaining predictors. For example, there was little difference in the results for solar cycle and QBO, whether polar vortex strength was added as predictor or not. Also, for various combinations of including or 


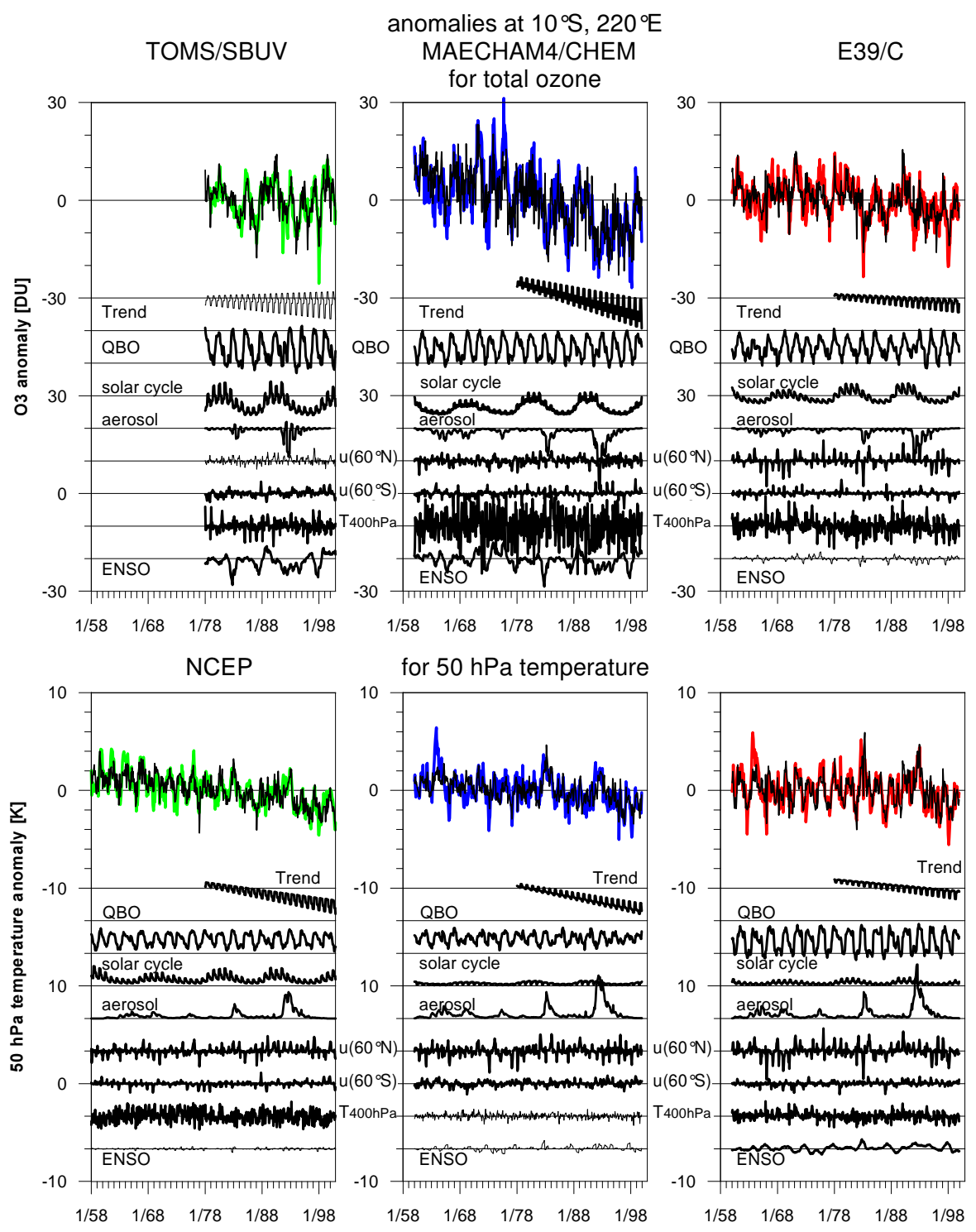

Fig. 2. Top panels: Total ozone anomalies at $10^{\circ} \mathrm{N}, 220^{\circ} \mathrm{E}$ for TOMS/SBUV observations (green, left column), MAECHAM4-CHEM simulation (blue, middle column), and E39/C simulation (red, right column). The corresponding regression results are given by the black lines. The top part of each panel shows observed or simulated anomalies, along with the regression results from Eq. (1). The lower parts show the individual terms $c_{X} X$ in the regression. They are plotted to the same scale as the anomalies, but have been shifted by arbitrary amounts. The two QBO terms have been combined into one. The thick lines indicate predictors that were significant in at least one season. Bottom panels: Same, but for $50 \mathrm{hPa}$ temperature.

excluding $T(400)$ and $E N S O$ as predictors, the results for the other predictors changed very little. Finally, we found that regression results change very little, whether data from the entire 1958 to 2000 period, or 1960 to 1999 for the simulations, or the much shorter 1979 to 2000 period where used. To summarize, in our experience the regression gives generally very stable and consistent results (see also Steinbrecht et al. (2003)).

\section{Results}

\subsection{Examples for time series}

Examples for total ozone and $50 \mathrm{hPa}$ temperature anomalies for a few selected grid-points, in tropics, northern midlatitudes and near the poles, are plotted in Figs. 2 to 5, along with the corresponding regression results. The grid points were selected to provide a examples where the regression works very well (Fig. 2), or very poorly (Fig. 3). The top of each panel shows observed or simulated anomalies from 

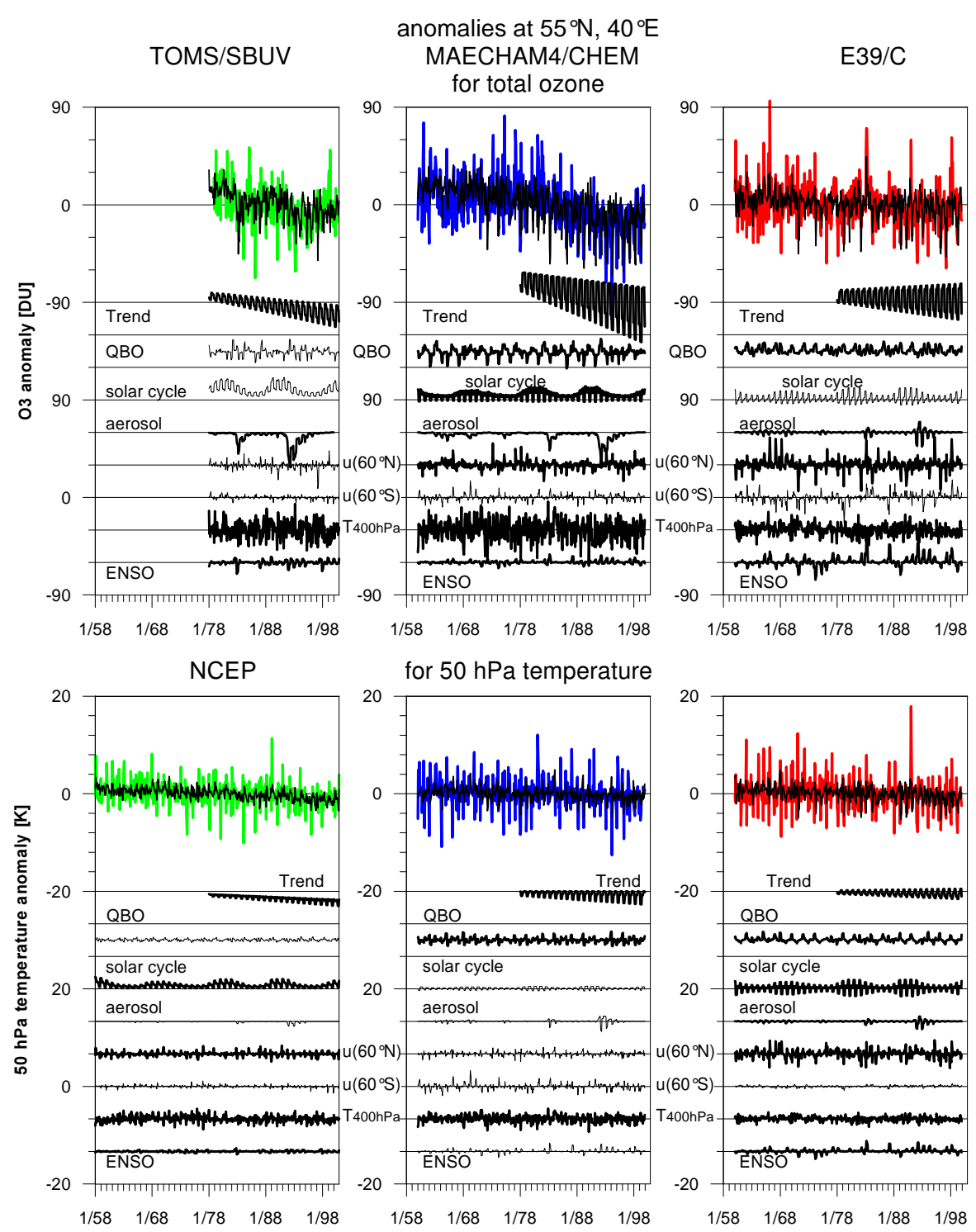

Fig. 3. Same as Fig. 2, but for the grid point nearest to $55^{\circ} \mathrm{N}, 40^{\circ} \mathrm{E}$.

MAECHAM4-CHEM and E39/C (all in colour), along with the anomaly time series resulting from regression according to Eq. (1). In the lower part of each panel the individual predictor terms $c_{X} X$ from Eq. (1) are plotted. Note that the two QBO terms have been combined into one. These terms represent ozone and temperature variations attributed to the various influences by the regression procedure. The striking sawtooth patterns, e.g. in trend term, or solar cycle term are a consequence of the annual cycle allowed for by carrying out the regression separately for the four seasons. The regression usually retrieves different coefficients $c_{X}$ for the four seasons, although the difference between seasons may not always be significant. Note that for Figs. 2 to 5, we have forced all predictors into the regression, whereas throughout most of the paper only the significant predictors are used.
The significant predictors are indicated by the thicker black lines in Figs. 2 to 5.

In general, regression results reproduce the observed or simulated anomaly time series. However, some of the larger and many of the smaller anomalies are not reproduced well. This is particularly true at mid-latitudes (Fig. 3). To some degree it has to be expected since the linear regression is only a simple approximation. It minimizes the mean square deviation between observed/simulated anomalies and regression result. The shape of each term $c_{X} X$ is prescribed completely by the shape of the predictor $X$ in Eq. (1). In nature or in the simulations, however, non-linear interactions occur. The response, e.g. to the QBO or ENSO, may be different between one cycle and another. The regression, however, assumes that the response always linearly follows the prescribed pre- 


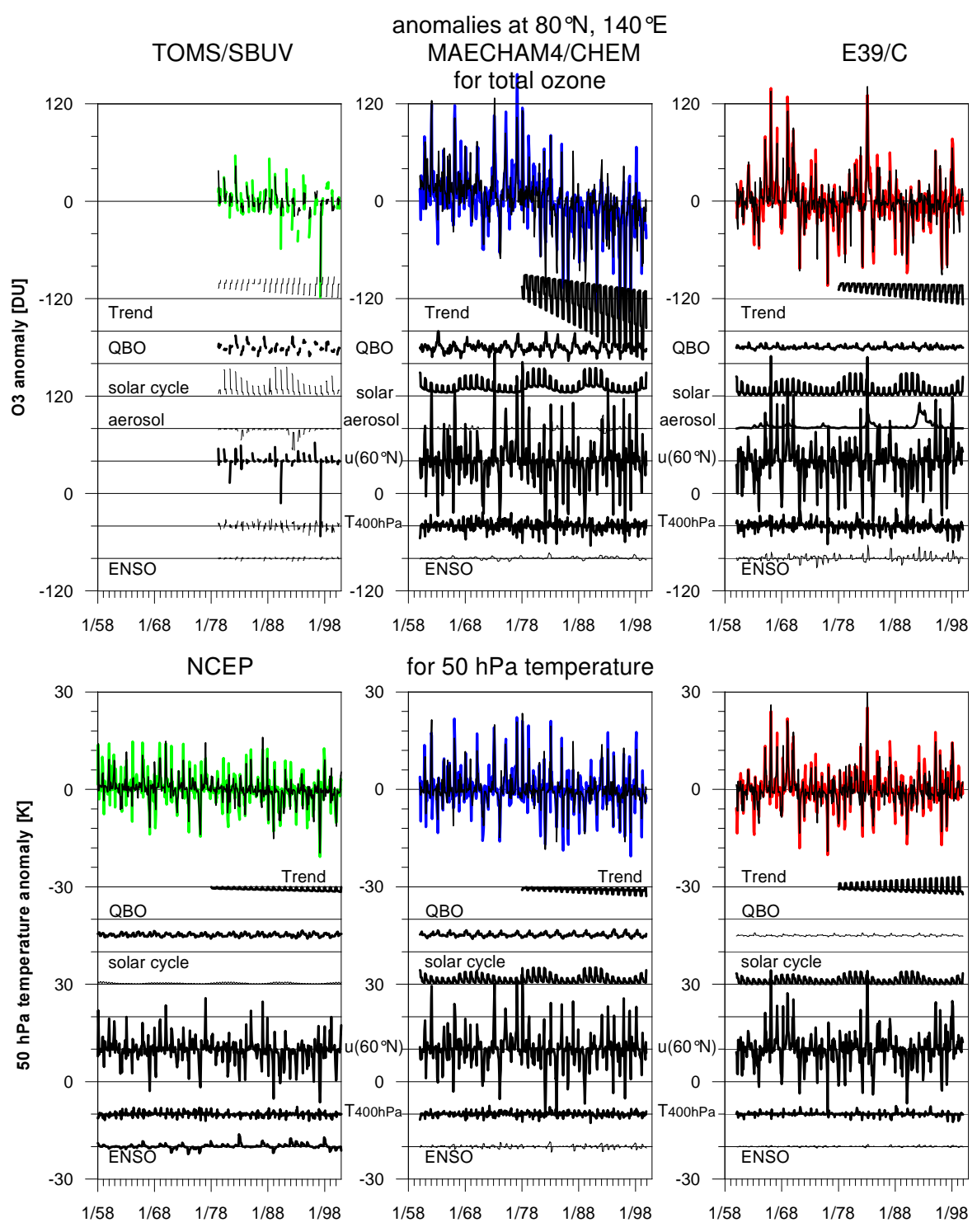

Fig. 4. Same as Fig. 2, but for the grid point nearest to $80^{\circ} \mathrm{N}, 140^{\circ}$ E. For clarity, the insignificant terms for aerosol and $u\left(60^{\circ} \mathrm{S}\right)$ have been omitted here.

dictor. Thus, the regression retrieves an "average" (mean square) response. This tends to give a correct average effect for individual influences/predictors, but anomalies can be underrepresented for a given single event. For example, results are quite uncertain for volcanic aerosol, where only two or three large events have occured. During these events the regression tends to attribute all variations to the volcanic aerosol predictor, that cannot be explained by the other predictors. To a lesser degree, the same applies to the ENSO predictor. Also, while the current set of predictors accounts for the most important global influences, predictors for more local influences may very well be missing.

At the the grid point near $10^{\circ} \mathrm{N}, 220^{\circ} \mathrm{E}$, a typical tropical grid point, the regression reproduces the observed and simulated anomalies fairly well (Fig. 2). Tropical anomalies are generally much smaller, and substantially less noisy than anomalies at higher latitudes (note the change of scale between Figs. 2 to 5). The noisy temperature signal at higher latitudes, e.g. in Fig. 3, is not reproduced well by the regression. Trend, QBO, solar-cycle and stratospheric aerosol usually give fairly regular variations. The other predictors, however, are noisy and chaotic. They give much less regular variations. Polar anomalies (Figs. 4 and 5) are dominated by winter extremes, which are associated with changes between a cold polar vortex and stratospheric winter warmings. In the regression this is accounted for by the zonal wind speed predictors at $60^{\circ}$ latitude, $50 \mathrm{hPa}$. Along with the total ozone trend, it is the dominating predictor for the polar regions. As 


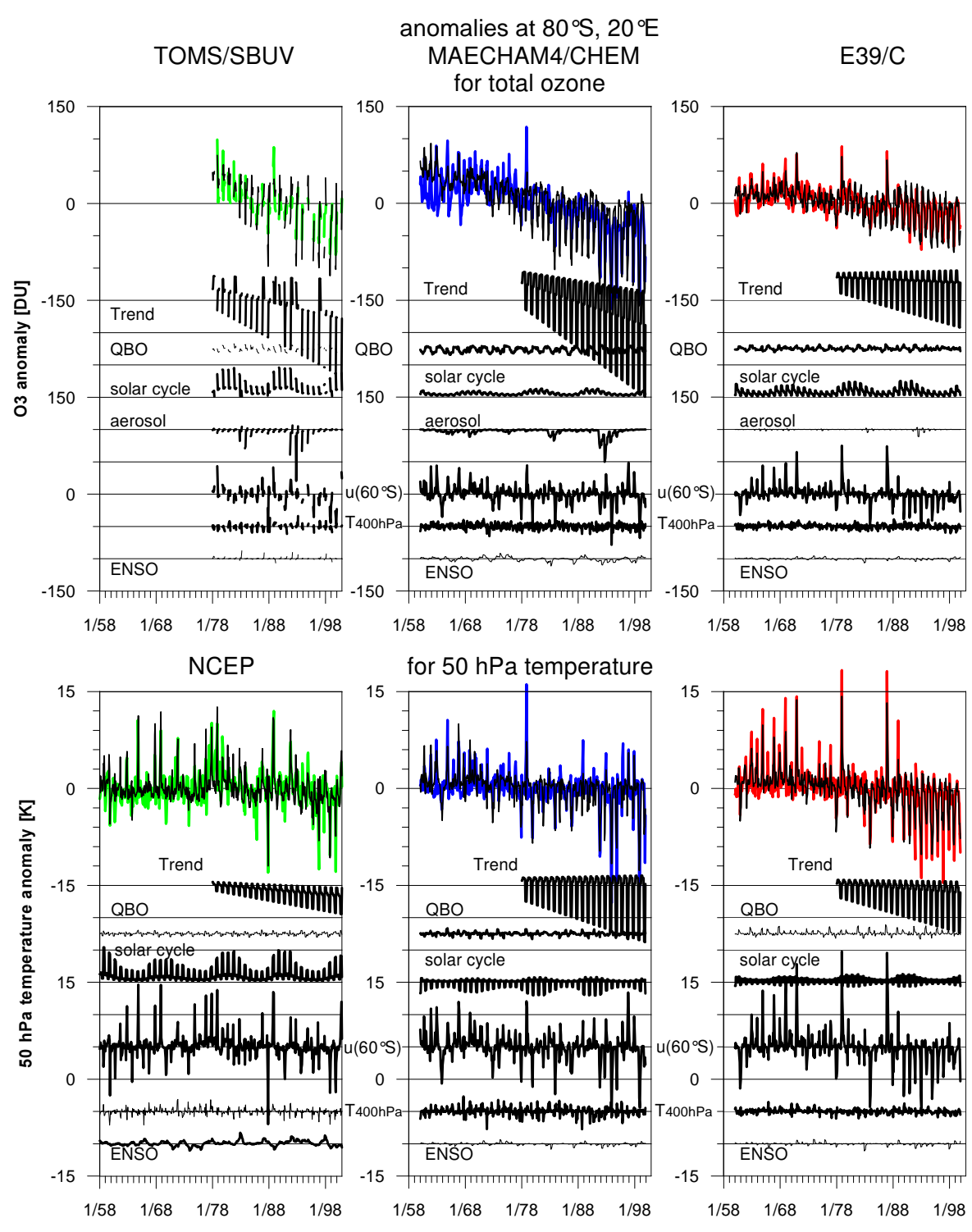

Fig. 5. Same as Fig. 2, but for the grid point nearest to $80^{\circ} \mathrm{S}, 20^{\circ}$ E. For clarity, the insignificant terms for aerosol and $u\left(60^{\circ} \mathrm{N}\right)$ have been omitted here.

mentioned before, the TOMS/SBUV data do not completely sample the polar regions in winter, especially the Arctic in the cold 1990s. This has to be accounted for when comparing observed and model trends. Trends are discussed in Sect. 3.3. In general, both simulations show variability and long-term changes that are comparable to the observations/reanalysis. Rather than discussing the time series plots in detail, we will now focus on describing the general performance of the regression, and the global patterns of the magnitude of ozone and $50 \mathrm{hPa}$ variations attributed to the various predictors.

\subsection{Variance described by regression}

An important measure for the performance of a regression is $R^{2}$, the ratio of the variance described by the regression, i.e. the variance of all terms on the right side of Eq. (1), except for the residual, to the total variance, i.e. to the variance of the left side of Eq. (1). A perfect regression has $R^{2}=1$ and fully explains the total variance. Small $R^{2} \approx 0$ indicates that the regression explains only a small part of the total variance. This can happen when random noise, atmospheric, or from a measurement, accounts for a large fraction of the total variance, or when important explanatory variables are missing.

Examples for the global distribution of $R^{2}$ from the regression according to Eq. (1), carried out independently 
TOMS (1979-2000)
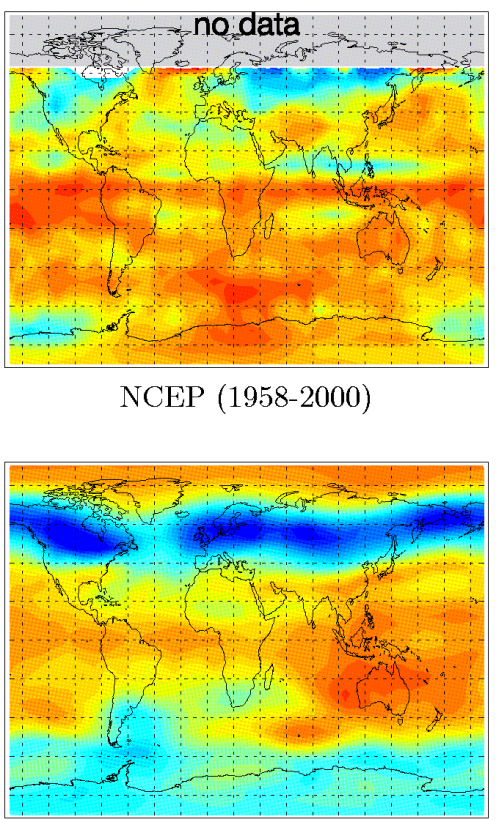

MAECHAM4-CHEM (1960-1999) $R^{2}$ for total ozone column, December/January/February

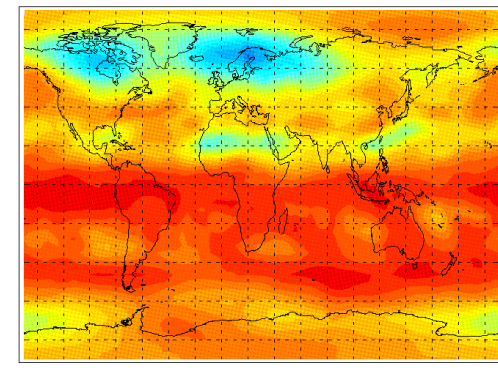

MAECHAM4-CHEM (1960-1999) $R^{2}$ for temperature at $50 \mathrm{hPa}$, December/January/February

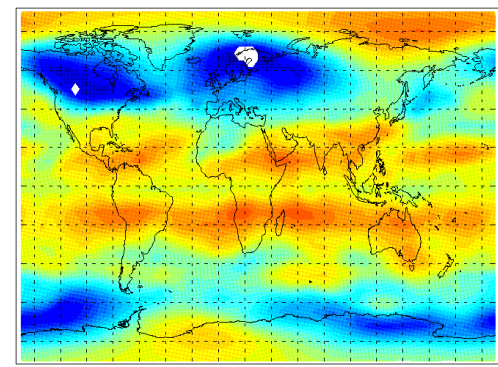

E39/C (1960-1999)

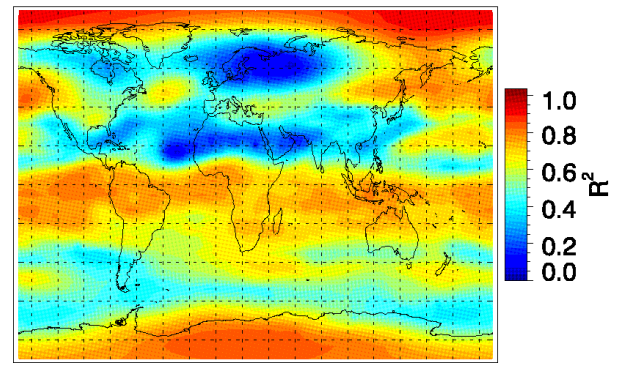

E39/C (1960-1999)

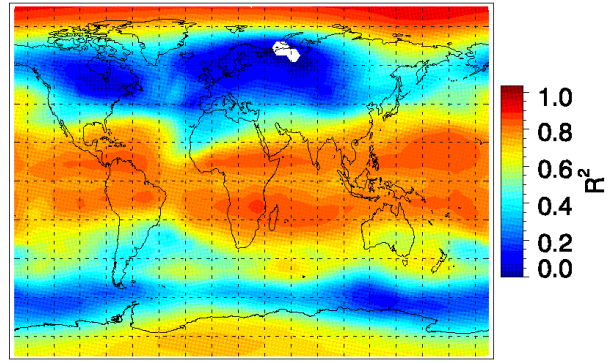

Fig. 6. Global maps of $R^{2}$ for northern winter (December/January/February). Top row gives results for total ozone anomalies, bottom row results for temperature anomalies at $50 \mathrm{hPa}(\approx 22 \mathrm{~km}) . R^{2}$ for TOMS/SBUV observations and NCEP reanalyses results is given in the left column, $R^{2}$ for the MAECHAM4-CHEM transient simulation in the middle column, and $R^{2}$ for the ECHAM4.L39(DLR)/CHEM (=E39/C) transient simulation in the right column. TOMS/SBUV observations are not available before 1979 and are not available in polar regions in winter (grey area).

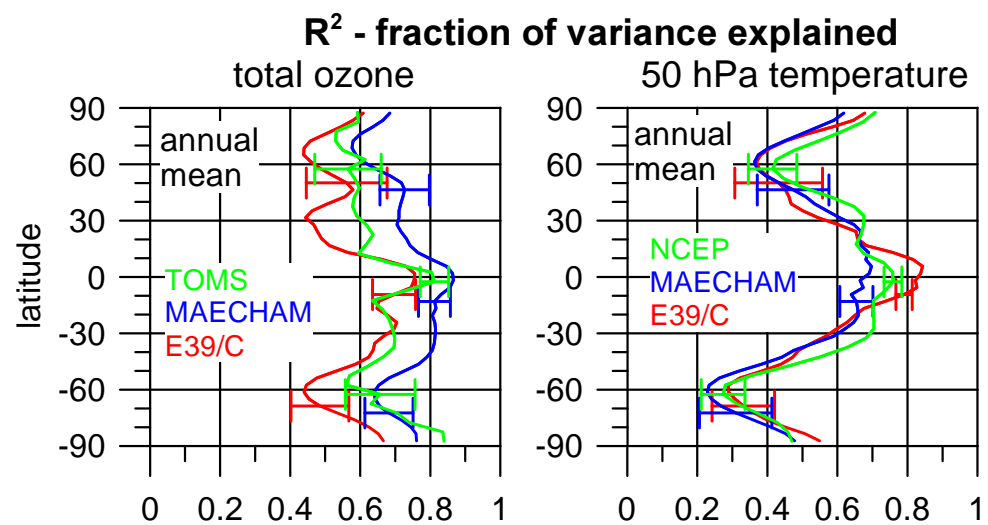

Fig. 7. Latitude dependence of annual mean zonal mean $R^{2}$ from the regression. Results were obtained by averaging the $R^{2}$ from the regression at each grid cell (Fig. 6) over all longitudes and over the four seasons. Error bars are 1 standard deviation over longitude, averaged over the four seasons, and give the typical $1 \sigma$ uncertainty for $R^{2}$. Left panel gives results for total ozone anomalies, right panel for temperature anomalies at $50 \mathrm{hPa}(\approx 22 \mathrm{~km})$. The considered time period is 1979 to 2000 for TOMS/SBUV total ozone, 1958 to 2000 for NCEP temperature, and 1960 to 1999 for the model simulations.

for each season and each grid point, are given for December/January/February in Fig. 6. For Fig. 6 and the following figures, we have chosen to select only one season, which presents a clear but typical example. If they appear important, differences in other seasons are mentioned. This ap- proach is easier to digest and less confusing than to show many figures with results for all four seasons. Values of $R^{2}$ larger than about 0.6 indicate that the regression describes a major part of the variance. $R^{2}$ smaller than 0.4 , however, indicates that the regression is not giving a good description. 
$R^{2}$ values are generally highest in winter and spring in the respective hemispheres, when variance is high, and are lower in summer and fall, when variance is low.

A zonal mean summary of $R^{2}$ achieved by the regressions is plotted in Fig. 7. This Figure shows zonal mean results obtained by averging the grid cell results from Fig. 6 over all longitudes and over the four seasons. The error bars give the standard deviation along one latitude, averaged over the four seasons. This standard deviation has contributions both from true longitudinal variations, and from noise remaining after the regression process. The error bars give a good representation of longitudinal variation and noise around the zonal mean result. Fig. 7 does not carry longitudinal information, but allows for a more direct comparison between the results for observations/reanalyses, and the model simulations.

Generally, the regression works better for total ozone (top panels of Fig. 6, left panel of Fig. 7) than for $50 \mathrm{hPa}$ temperature (bottom panels of Fig. 6, right panel of Fig. 7). Geographically, it works best in the tropics, subtropics, and in polar regions. Around $60^{\circ}$ latitude, there are substantial belts where $R^{2}$ can go below 0.4 and the regression often does a poor job (compare Fig. 3). These belts are less pronounced in total ozone, more pronounced in $50 \mathrm{hPa}$ temperature. They correspond to the storm track and jet-stream regions, also to the region of breaking planetary waves and to the edge of the polar vortex. Obviously, no simple predictor is included in Eq. (1) to account for such more complex phenomena. Also, by using monthly mean data, non-linear phenomena like shorter life-time storms or jet-streams, breaking waves and shorter term variations of the polar vortex edge might be averaged out inappropriately. Examples of the time series at typical grid-points for the different regions have been shown and discussed with Figs. 2 to 5.

As mentioned, the regression can account for more than $60 \%$ of the total ozone variance, and for mor than $50 \%$ of the $50 \mathrm{hPa}$ temperature variance over a large part of the globe. For $50 \mathrm{hPa}$ temperature, there is little difference between the $R^{2}$ obtained for the NCEP reanalyses, or for the two model simulations. For total ozone, there is less difference between latitude bands than for $50 \mathrm{hPa}$ temperature. The highest total ozone $R^{2}$, almost 0.8 , is obtained for the MAECHAM4CHEM simulation. About $10 \%$ less of the variance are explained for the TOMS/SBUV observations. The lowest total ozone $R^{2}$ is found for E39/C total ozone. While the general patterns for observations and both simulations are comparable, E39/C seems to have additional variance that is not captured by the present set of predictors. At present it is not clear whether this is a result of the additional levels near the tropopause, the somewhat more diffusive transport, or the very low uppermost layer at $10 \mathrm{hPa}$. Over large areas of the globe, and for observations and simulations, however, the very simple multiple linear regression with just a handful of predictors accounts for a substantial fraction of observed and simulated total ozone and $50 \mathrm{hPa}$ temperature variance.

\subsection{Linear trend}

Linear trends cofficients $c_{T R}$ from Eq. (1), obtained for the 1979 to 2000 period for the observations, and for the 1978 to 1999 period for the simulations, are plotted in Fig. 8, for northern spring (March/April/May). The corresponding zonal mean trends are shown in Fig. 9 for northern spring (March/April/May) and southern (September/October/November) spring, in the respective hemisphere. Similar to Fig. 7, the zonal means were obtained by averging the grid cell results (Fig. 8) over all longitudes. The error bars give the standard deviation along one latitude. Note that in Fig. 8, and the following false colour figures, white areas indicate that the trend term (or the respective terms in the following figures) was not statistically significant at these grid points, at the $90 \%$ confidence level.

The largest total ozone trends are found at high latitudes in spring of the respective hemisphere. Winter trends are somewhat smaller than spring trends. Note, however, that the true long-term decline in winter and spring above the Arctic may be underestimated by a lack of TOMS/SBUV observations in winter, particularly in the cold 1990s. The smallest trends are found in fall and summer for the respective hemisphere. Trends for southern spring at high southern latitudes are substantially larger than at high northern latitudes for northern spring (Fig. 9). Ozone decline is lowest in the tropics.

The simulations reproduce this main latitudinal structure of the observed ozone trend, with small trends in the tropics and high trends at high latitudes. The seasonal variation with highest trends in spring, and lowest trends in the fall is also captured by the simulations. However, the MAECHAM4CHEM simulated trend is generally too large everywhere, by about -6 DU/decade, especially too large at northern high latitudes. This shift towards larger total ozone decline is largely due to two factors: A.) MAECHAM4-CHEM has too high $\mathrm{ClO}$ in the upper stratosphere, which results in too large ozone decline in the upper stratosphere. Since upper stratospheric ozone is transported to lower levels, some of this too large upper stratospheric decline shows up in total ozone. B.) MAECHAM4-CHEM does not include a complete chemical scheme for tropospheric ozone and does not include complete tropospheric precursor emission. Thus MAECHAM4CHEM does not reproduce the observed increase of tropospheric ozone. This also contributes to a more negative trend in total ozone.

The polar cold bias in the model (Austin et al., 2003) may tend to contribute to the large simulated decline at northern high latitudes. It is important to note, however, that no TOMS/SBUV observations are available in many of the winters with large ozone depletion in the 1990s (Fig. 1. It is, therefore, quite likely that the true total ozone trend above the Arctic is larger than observed by the combined TOMS/SBUV data-set.

The E39/C simulated total ozone trend shows slightly smaller than observed trends at northern mid-latitudes, and 
TOMS (1979-2000)

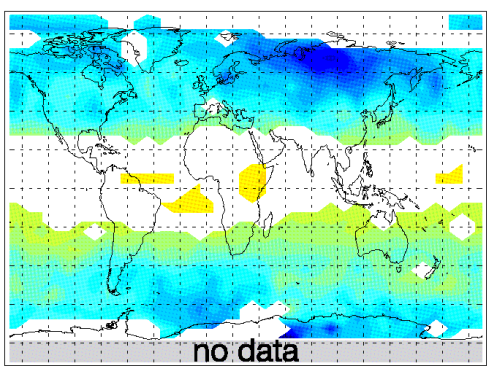

NCEP (1979-2000)

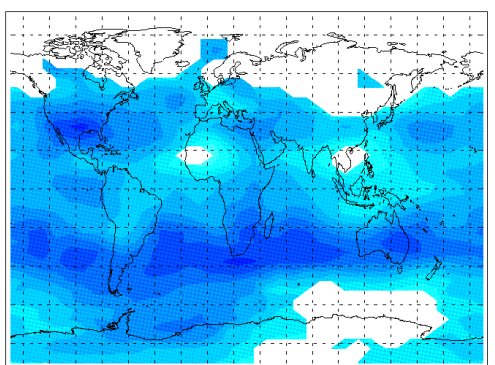

MAECHAM4-CHEM (1978-1999) linear trend for total ozone column, March/April/May

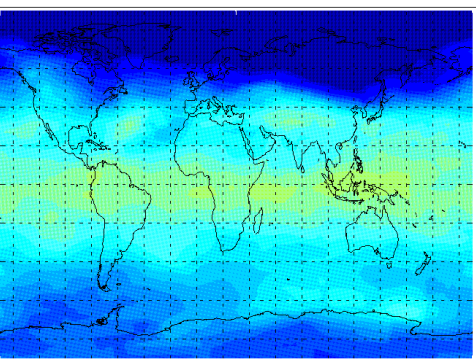

MAECHAM4-CHEM (1978-1999) linear trend for temperature at $50 \mathrm{hPa}$, March/April/May

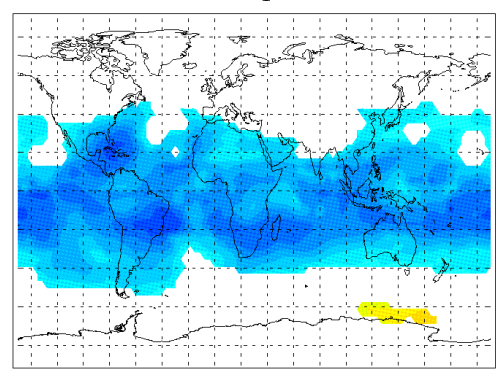

E39/C (1978-1999)

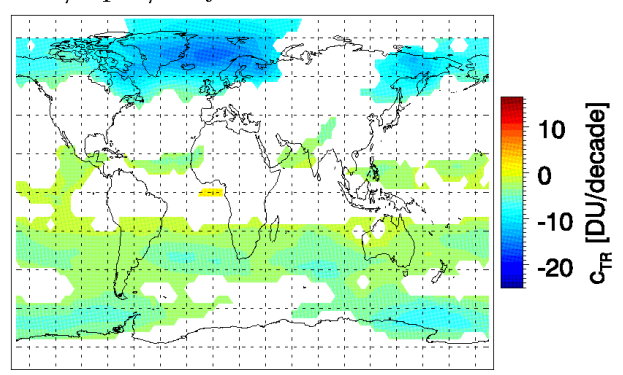

$\mathrm{E} 39 / \mathrm{C}(1978-1999)$

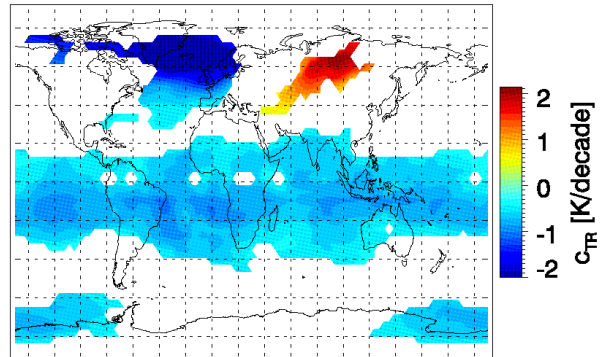

Fig. 8. Same as Fig. 6, but showing the linear trend coefficient for northern spring (March/April/May). Top panels give the total ozone trend coefficient in DU per decade, bottom panels give the temperature trend coefficient in K per decade for $50 \mathrm{hPa}(\approx 22 \mathrm{~km})$. The time period is 1979 to 2000 for observations/reanalysis in the left column and is 1978 to 1999 for the model runs in the middle and right column. In the white regions the linear trend term is not statistically significant at the $90 \%$ confidence level.
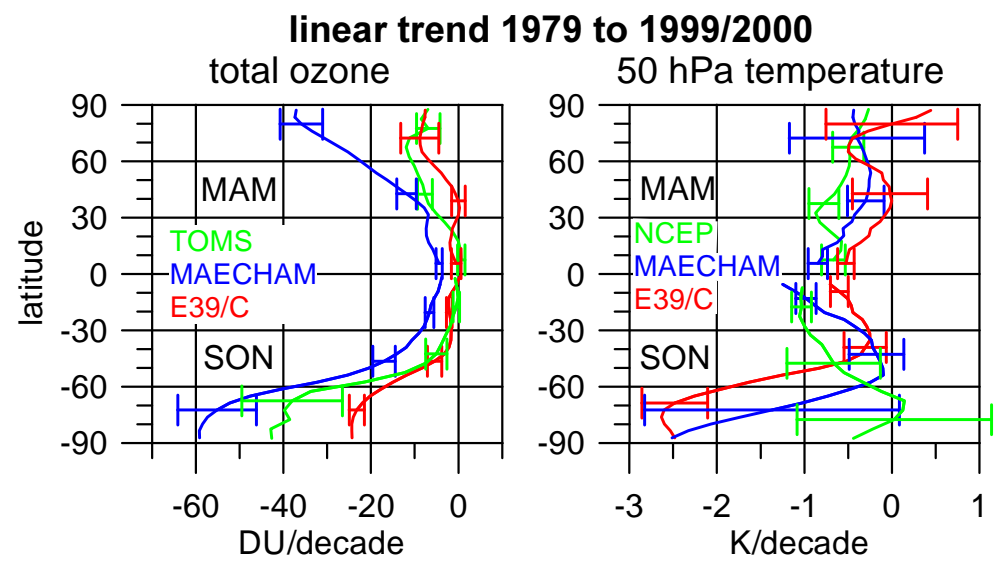

Fig. 9. Latitude dependence of zonal mean linear trends in spring. Note that March/ April/ May data are used for the Northern Hemisphere, and September/ October/ November are used in the Southern Hemisphere. Results were obtained by averaging the linear trend coefficients from the regression at each grid cell (Fig. 8) over all longitudes. Error bars are 1 standard deviation over longitude, and give the typical $1 \sigma$ uncertainty for the trend coefficient. Left panel gives results for total ozone anomalies, right panel for temperature anomalies at $50 \mathrm{hPa}$ $(\approx 22 \mathrm{~km})$. The considered time period is 1979 to 2000 for TOMS/SBUV total ozone and NCEP temperature, and 1979 to 1999 for the model simulations.

substantially smaller trends at southern high-latitudes. The smaller E39/C trends at northern mid-latitudes are at least partially due to the cold pole bias in this model. The polar vortex is generally to stable, lasts too long, and does not break up early enough (Hein et al., 2001; Austin et al., 2003). There- fore not enough ozone depleted air is exported from the Arctic vortex to mid-latitudes. Underestimation of the true total ozone trend due to the TOMS/SBUV sampling may also play a role. The reason for the too small Antarctic spring trend, however, is not clear at this point. Quite likely, the low top 
layer at only $10 \mathrm{hPa}$ in this model fails to correctly simulate the strong diabatic downward transport of various trace gases, e.g. ozone and $\mathrm{ClO}_{\mathrm{x}}$, in the Antarctic winter vortex (Hein et al., 2001; Dameris et al., 2005). Figure 8 might also indicate that zonal asymetries have some influence on the smaller trends simulated by E39/C. The Figure shows, for example, a difference in the longitudinally varying structures at high latitudes. Observations and MAECHAM4-CHEM simulation indicate the largest March/April/May total ozone trends above Sibiria, whereas the E39/C simulation places them over the North Atlantic.

Before looking at temperature trends, a word of caution has to be said about using NCEP, or other reanalyses, to retrieve long-term trends. Although the analysis system is kept constant in the NCEP reanalysis, availability and quality of the input observational data does change over time. These changes are nearly inevitable and can affect the long-term consistency of reanalysis data. The most major change in the NCEP reanalysis was the introduction of global satellite observations in 1978/1979 (Kistler et al., 2001). Effects of this change have been shown in Fig. 1. They are most obvious in the Southern Hemisphere, where radiosonde data are sparse. After 1979 changes in the observation system kept occuring, e.g. due to satellite changes. It has been shown that these changes can lead to important problems with tropospheric temperature trends in the NCEP reanalysis (Hurrell and Trenberth, 1998; Santer et al., 2004). For the lower stratosphere, and after 1979, however, the problem seems to be much less severe (Ramaswamy et al., 2001). Nevertheless, the $50 \mathrm{hPa}$ NCEP temperature trends here have to be taken with some caution, particularly in the Southern Hemisphere.

Given this caveat, $50 \mathrm{hPa}$ temperatures from NCEP reanalysis and from both simulations agree on substantial longterm cooling, by 0.5 up to $1 \mathrm{~K} /$ decade in a broad band from roughly $40^{\circ} \mathrm{S}$ to $40^{\circ} \mathrm{N}$ (Figs. 8 and 9). Around $40^{\circ}$ in both hemispheres, the simulations report a minimum that is not seen at these latitudes in the NCEP reanalysis (Fig. 9). At higher latitudes the error bars increase. Cooling and differences are often not significant. As with total ozone, the E39/C simulation shows a latitudinally varying cooling/warming pattern above the North Atlantic/Asia that is not seen in NCEP reanalyis or the MAECHAM4-CHEM simulation (Fig. 8). Except for the polar caps, very similar cooling is found in other seasons (not shown), both in simulations and NCEP reanalysis.

In southern spring both simulations report very large and significant cooling by 2 to $3 \mathrm{~K} / \mathrm{decade}$ south of $60^{\circ}$ to $80^{\circ} \mathrm{N}$ (Fig. 9). This cooling is due to the simulated ozone depletion, but it is not seen in the NCEP reanalysis. At this point, it is unclear whether this difference is caused by the discussed data consistency problem in the Southern Hemisphere NCEP reanalysis (see Fig. 1 before 1979), or whether it is related to the general polar vortex cold bias of the model simulations (Austin et al., 2003). In general, however, and at many latitudes the MAECHAM4-CHEM simulations repro- duce the magnitude of the long-term cooling derived from the NCEP reanalysis, whereas E39/C tends to show smaller cooling trends.

The observed temperature and ozone trends from Fig. 8 agree with results from other studies (Ramaswamy et al., 2001; Fioletov et al., 2002; WMO, 2003). The major part of the declining trend in total ozone must be attributed to increasing anthropogenic chlorine and bromine (WMO, 2003). Lower stratospheric cooling, on the other hand is attributed to decreasing lower stratospheric ozone levels, and to increasing $\mathrm{CO}_{2}$ and water vapour (IPCC, 2001; WMO, 2003; Shine et al., 2003).

Recently, chlorine levels seem to have begun decreasing in the stratosphere (WMO, 2003; Rinsland et al., 2003). It is now being discussed whether ozone also might show signs of a beginning recovery (Newchurch et al., 2003; Steinbrecht et al., 2004; Reinsel et al., 2005). Unfortunately, the simulations have not yet been extended past 1999. This is planned for the near future and would help to address questions about a beginning ozone recovery. Especially for studies using the newer data after 2000, where ozone levels appear to have levelled off (Reinsel et al., 2005), it will be important to not assume a linear trend throughout the entire time series anymore. For the present study using the 1979 to 1999/2000 time period only, however, this levelling off is a minor effect and a simple linear trend is still acceptable.

\subsection{Quasi-Biennial Oscillation}

Figure 10 shows the typical amplitude (valley to peak) of total ozone and temperature variations that are correlated with the QBO. Figure 11 shows the corresponding annual mean zonal mean magnitudes, obtained by averaging over longitudes and over the four seasons. Plotted is twice the temporal standard deviation (i.e. $2 \sigma$ ) of the combined QBO time series term $c_{Q B O(10)} Q B O(10)+c_{Q B O(30)} Q B O(30)$ in Eq. (1). Examples for these time series have been given in Figs. 2 to 5. Two standard deviations essentially give the average minimum to maximum swing of the variations attributed to given influence, and are a good measure of the magnitude of ozone and temperature variations correlated, e.g. with the QBO. It should not be confused with the uncertainty of coefficients $c_{X}$ derived by the regression according to Eq. (1), or with the longitudinal error bars plotted in Fig. 11. Rather than showing the coefficients $c_{X}$ directly, we have chosen to plot this measure of the temporal variation of the associated time series terms $c_{X} X$ in Eq. (1), because it allows for a direct comparison with the magnitudes of the other terms, measured in DU or K, respectively. This comparison is not possible for the coefficients, which have units of $\mathrm{DU} /(\mathrm{m} / \mathrm{s})$ for the QBO, but e.g. units of $\mathrm{DU} /\left(\mathrm{W} / \mathrm{m}^{2} / \mathrm{Hz}\right)$ for the solar cycle. Note that the second scales in Figs. 10 and 11 give the approximate size of the coefficents from Eq. (1).

Since QBO winds at 10 and $30 \mathrm{hPa}$ are nearly $90^{\circ}$ out of phase, the use of the two QBO levels in Eq. (1) allows for 


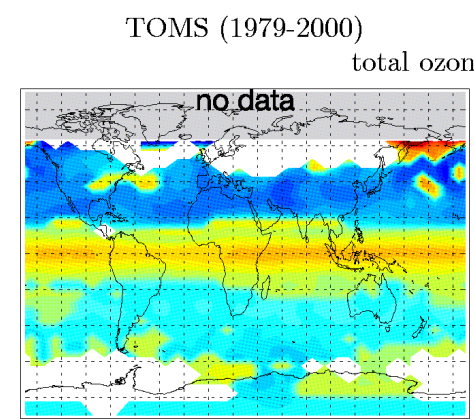

NCEP (1958-2000)
MAECHAM4-CHEM (1978-1999)

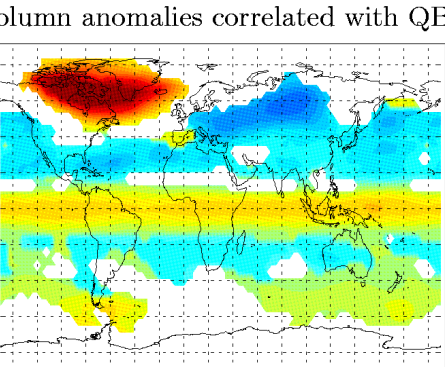

MAECHAM4-CHEM (1960-1999)
E39/C (1978-1999)

ry/February

temperature anomalies at $50 \mathrm{hPa}$ correlated with QBO, December/January/February
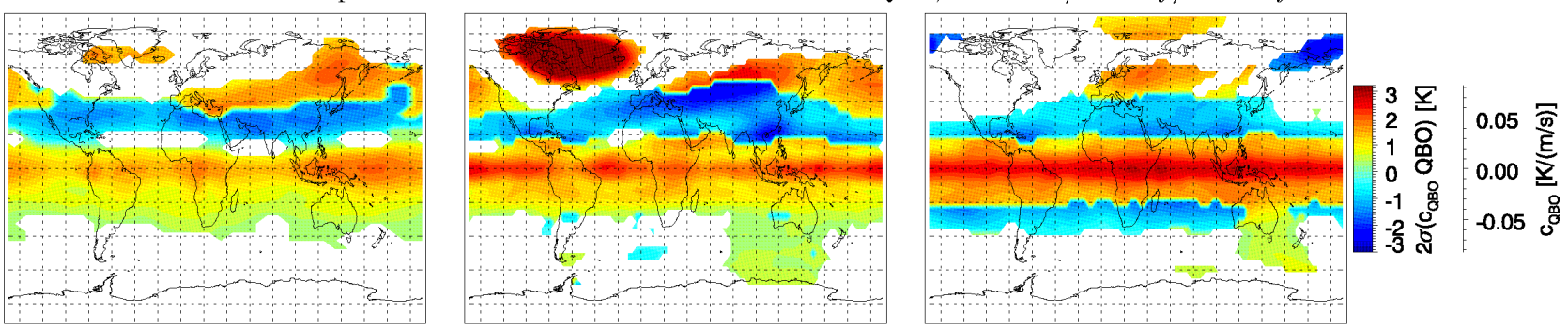

Fig. 10. Similar to Fig. 8 , but showing two standard deviations $(2 \sigma)$ of the combined QBO term $2 \sigma\left(c_{Q B O(10)} Q B O(10)+c_{Q B O(30)} Q B O(30)\right)$ in the regression, for northern winter (December/January/February). The second scales, on the right, give the approximate size of the QBO regression coefficient $\sqrt{c_{Q B O(10)}^{2}+c_{Q B O(30)}^{2}}$. Blue colours indicate inverse (negative) correlation with westerly zonal wind at $30 \mathrm{hPa}$ at the Equator, whereas yellow and red colours indicate positive correlation. For total ozone in the top panels a shorter time period is considered. White regions have no statistically significant QBO-related variation, at the $90 \%$ confidence level.
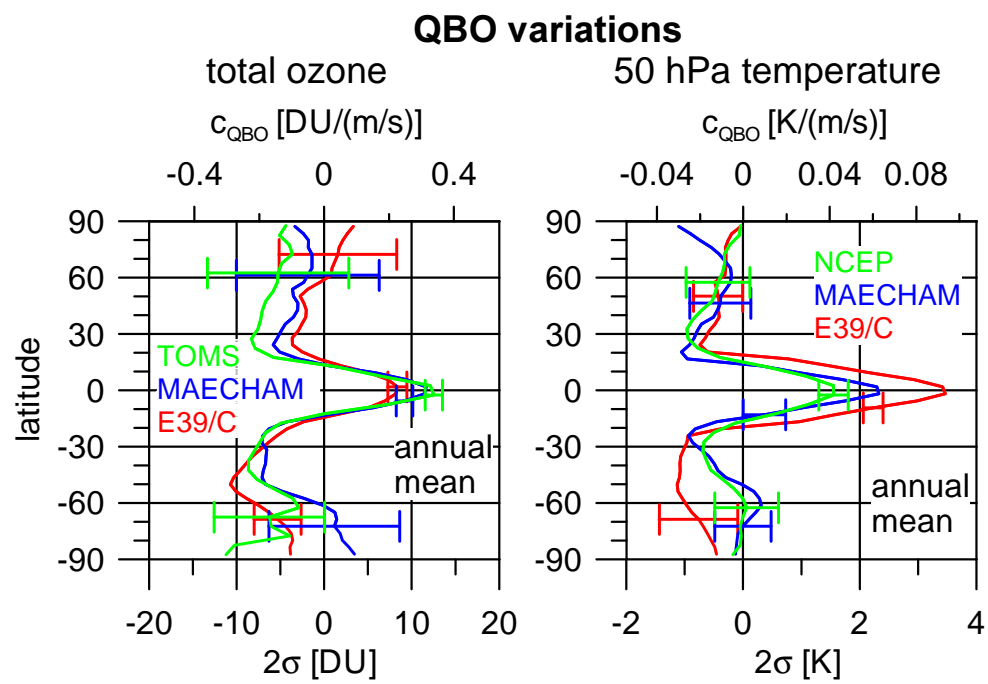

Fig. 11. Similar to Fig. 9, but showing the latitude dependence of the annual mean size of QBO-related total ozone and $50 \mathrm{hPa}$ temperature variations. Results were obtained by averaging the grid cell results from Fig. 10 over all longitudes and over the four seasons. Error bars are 1 standard deviation over longitude, averaged over the four seasons. This gives the typical $1 \sigma$ uncertainty for the magnitude of QBO-related variations. Left panel gives results for total ozone anomalies, right panel for temperature anomalies at $50 \mathrm{hPa}(\approx 22 \mathrm{~km})$. The considered time period is 1979 to $1999 / 2000$ for total ozone, and 1958 to $1999 / 200050 \mathrm{hPa}$ temperature. The second scale, at the top, gives the approximate size of the QBO regression coefficients. 
an automatic adjustment of the QBO ozone or temperature signal to the proper phase. In Fig. 10, yellow and red colours indicate positive correlation between ozone or temperature anomalies and Equatorial wind anomalies at $30 \mathrm{hPa}$ (i.e. high during westerly winds), whereas cyan and blue colours indicate inverse correlation (low during westerly winds).

The first thing to note in Figs. 10 and 11 is the remarkable similarity between the $\mathrm{QBO}$ variation patterns of total ozone and lower stratospheric temperature at $50 \mathrm{hPa}$. For each individual data set, i.e. for observations, MAECHAM4-CHEM, and E39/C simulation respectively, the two sub-panels look quite similar. 10 to 20 Dobson Units QBO-related ozone change roughly correspond to a 1 to $2 \mathrm{~K}$ QBO-related temperature change. During the QBO westerly phase (at $30 \mathrm{hPa}$ ) total ozone and $50 \mathrm{hPa}$ temperature are above normal in the tropics, within $15^{\circ}$ to $20^{\circ}$ of the equator, and are below normal in the sub-tropics. This is due to a QBO-induced secondary circulation (Baldwin et al., 2001). At the time of westerly winds at $30 \mathrm{hPa}$ this secondary circulation decreases upwelling and adiabatic cooling of ozone poor air in the tropics, thereby increasing total ozone and warming the lower stratosphere (red belt at the Equator in Fig. 10, high ozone and temperatures in Fig. 11). In the extratropics the same secondary circulation decreases downwelling and adiabatic warming of ozone-rich air. This results in the blue regions of low total ozone and low $50 \mathrm{hPa}$ temperature in the subtropics in Fig. 10, or in below average total ozone and temperatures polewards of $20^{\circ}$ in Fig. 11. Note that QBO effects are largest in the winter and spring hemisphere.

At latitudes equatorwards of $30^{\circ}$ to $40^{\circ}$, both model simulations reproduce the observed QBO-related variations quite well. This has to be expected, since in both simulations the QBO in zonal wind is enforced by a nudging procedure (Giorgetta and Bengtsson, 1999). After nudging, the secondary meridional circulation of the QBO and the related effects in temperature and ozone column result from the simulated dynamics of the model (Giorgetta et al., 2002). In the tropics and the Northern Hemisphere E39/C shows a more pronounced QBO signal in $50 \mathrm{hPa}$ temperature, and a less pronounced signal in total ozone. Probably, the higher temperatures result in increased chemical ozone destruction, and thus reduce the $\mathrm{E} 39 / \mathrm{C}$ total ozone $\mathrm{QBO}$ signal.

Polewards of about $40^{\circ}$ latitude, the zonal symmetry of the QBO-related patterns breaks down (Fig. 10). There, regions with large amplitudes and with positive correlation of total ozone or temperature to $30 \mathrm{hPa} \mathrm{QBO}$ winds appear over the Labrador sea, or in a band reaching from the Mediterranean Sea to the Aleutians. This apparent phase change around $40^{\circ}$ has been described, e.g. by Yang and Tung (1995). In the annual mean zonal mean results of Fig. 11 it has been smeared out and is hardly visible. Despite obvious differences, the MAECHAM4-CHEM simulation reproduces these observed zonally non-symmetric patterns better than the E39/C simulation. Similarly, in Fig. 11, the zonal mean results from MAECHAM4-CHEM tend to agree better with the obser- vational results. Since QBO effects reach up to $1 \mathrm{hPa}$ and above, it is not surprising that MAECHAM4-CHEM reacts in a more realistic way than $\mathrm{E} 39 / \mathrm{C}$, where the highest model level is around $10 \mathrm{hPa}$. Overall, our results indicate that both models propagate the nudged QBO wind variations in a realistic way to the simulated total ozone and $50 \mathrm{hPa}$ temperature fields.

\subsection{1-year solar cycle}

Figure 12 shows the amplitude of variations correlated with the 11-year solar cycle, for northern winter. The corresponding zonal mean, annual mean picture is given in Fig. 13. Again, total ozone and $50 \mathrm{hPa}$ temperature show similar patterns. Generally, both models slightly underestimate the observed amplitudes (Fig. 13), but reproduce the general patterns quite well, especially in the equatorial region and summer (southern) hemisphere (Fig. 12). Total ozone and $50 \mathrm{hPa}$ temperature are higher during solar maxima and lower during solar minima. At low and mid-latitudes, the amplitudes typically reach 5 to $10 \mathrm{DU}$ or 0.5 to $1 \mathrm{~K}$ between solar minimum and maximum, and the patterns are zonally symmetric. Up to $30^{\circ}$ to $50^{\circ}$ latitude, the amplitudes increase with distance from the Equator. The ozone signal is similar in observations and MAECHAM4-CHEM simulation, but smaller in the E39/C simulation. The temperature signal is about $0.5 \mathrm{~K}$ in the NCEP reanalysis, but less than $0.5 \mathrm{~K}$ in the simulations, where it seems to be missing near the Equator. There is little seasonal variation in the solar cycle signal at latitudes lower than about $40^{\circ}$.

Interestingly, solar cycle variations are largest, up to $30 \mathrm{DU}$ or $3 \mathrm{~K}$ at high latitudes. These patterns are not zonally symmetric, and are found primarily near the polar vortices, and in winter and spring of the respective hemisphere, e.g. in December/January/February in the Northern Hemisphere (Fig. 12) and in September/October/November in the Southern Hemisphere (not shown). The simulations reproduce the large amplitudes of these zonally asymmetric high latitude patterns, but not their position. The simulated patterns are shifted to different longitudes.

Especially for total ozone, the MAECHAM4-CHEM simulation reproduces the observed latitudinal variation better than the E39/C simulation (Fig. 13). This is not surprising, since it has to be expected that processes above $10 \mathrm{hPa}$ play a substantial role in the solar cycle signal in total ozone. For example, the meridional Brewer/Dobson circulation should be represented better in MAECHAM4-CHEM . It transports the fairly large (5\%) solar signal observed in low and midlatitude upper stratospheric ozone (e.g. Newchurch et al., 2003; Steinbrecht et al., 2004) to certain regions near the winter poles (Tourpali et al., 2003, 2005). For $50 \mathrm{hPa}$ temperature at latitudes lower than about $30^{\circ}$, both models show a weaker solar cycle signal than the NCEP reanalysis.

As discussed in the context of temperature trends, inconsistencies in the underlying observation systems may affect 


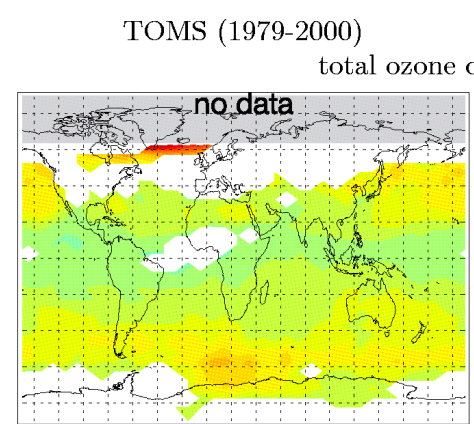

NCEP (1958-2000)
MAECHAM4-CHEM (1978-1999)

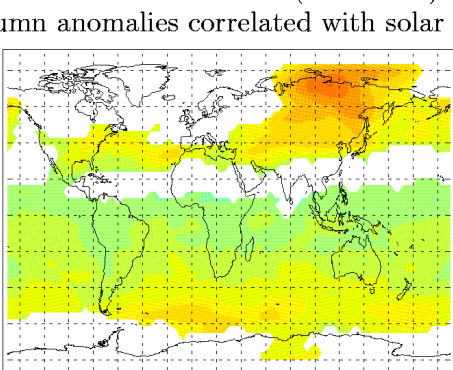

MAECHAM4-CHEM (1960-1999)

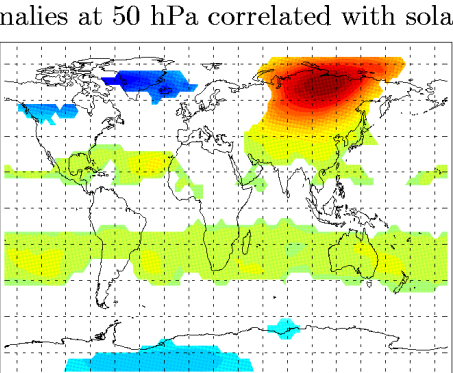

E39/C (1978-1999)

cle, December/January/February

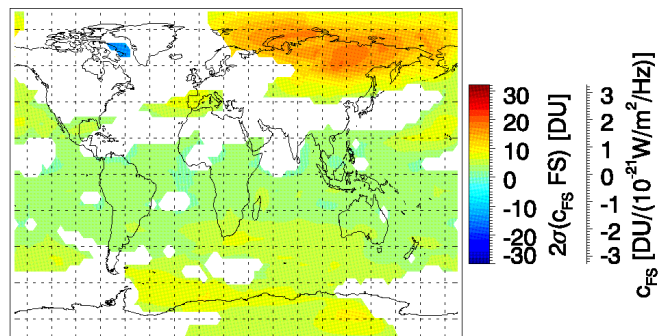

E39/C (1960-1999)

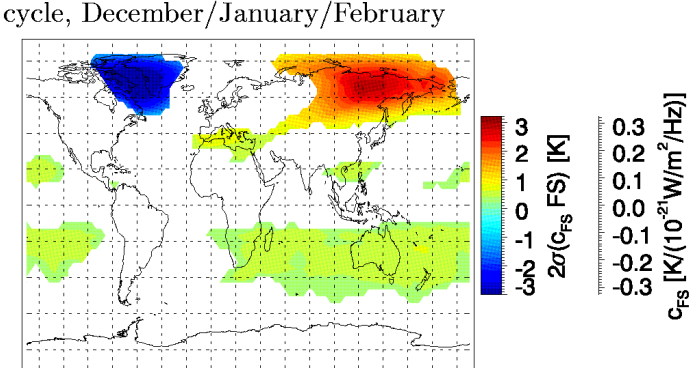

Fig. 12. Same as Fig. 10, but for the size $(2 \sigma)$ of total ozone and temperature anomalies associated with the 11-year solar cycle. The scales on the false colour bars give 2 standard deviations $(2 \sigma)$ of the solar cycle term $c_{F S} F S$ in Eq. (1). The second scales give the size of the solar cycle regression coefficient $c_{F S}$. Yellow and red colours indicate positive correlation between total ozone and solar flux.
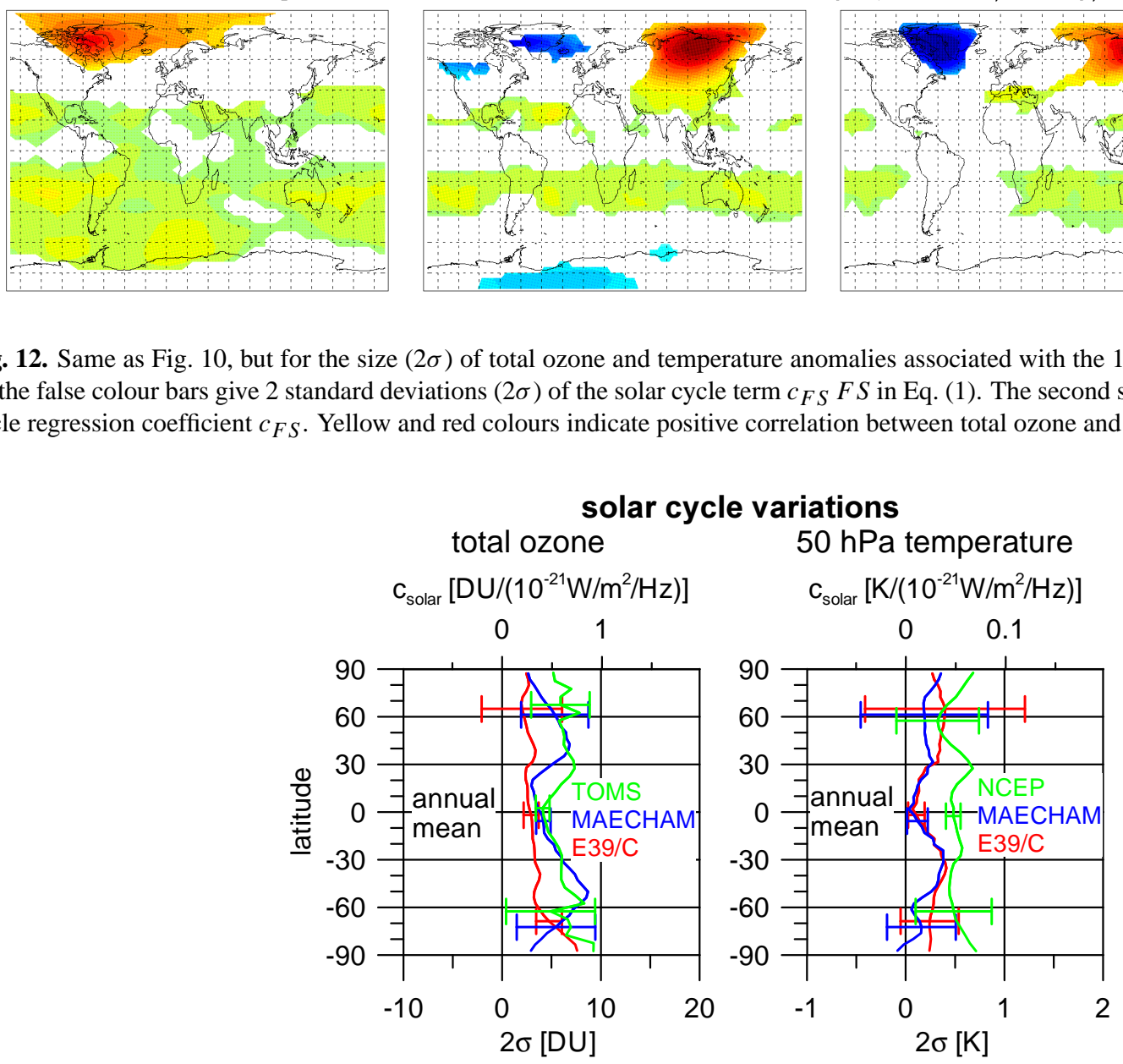

Fig. 13. Similar to Fig. 11, but showing the latitude dependence of the annual mean size of solar cycle related total ozone and 50 hPa temperature variations. The second scale, at the top, gives the size of the solar cycle regression coefficients.

the reanalysis and the $50 \mathrm{hPa}$ temperature solar cycle signal derived from it. However, we think that this is a minor effect: Despite the large and obvious change by introducing satellite observations in 1978/79, we find nearly the same magnitude and patterns for the solar effect, whether using the entire 1958 to 2000 data set, or only 1979 to 2000 . Secondly, the generally similar patterns between the solar cycle effect for total ozone and for $50 \mathrm{hPa}$ temperature both in simulations and observations also indicate that the solar cycle effect in the NCEP reanalysis is realistic.

These results for total ozone and $50 \mathrm{hPa}$ temperature are broadly consistent with previous results for stratospheric temperatures or total ozone (Zerefos et al., 1997; Hood, 1997; Labitzke et al., 2002). As pointed out by Lee and 
Smith (2003), regression on data spanning only a few solar cycles probably cannot separate QBO and solar cycle effects completely. Conceptual models indicate that QBO and solar cycle can interact with atmospheric noise to change the probability for warm or cold stratospheric winters (Ruzmaikin and Feynman, 2002). This has not been considered here. According to Hood (1997), observed changes in lower stratospheric dynamics can explain the total ozone fluctuations and their similarity to the temperature fluctuations. However, general circulation models even including a representation of atmospheric chemistry, largely have not been able to reproduce the full size of the variations observed in the lower stratosphere (Labitzke et al., 2002; Tourpali et al., 2003), particularly at higher latitudes. Progress has been made, e.g. by including the equatorial QBO Matthes et al. (2004). The MAECHAM4-CHEM simulation, and to a lesser degree the E39/C simulation are also a step towards a fairly good representation of the 11-year solar cycle, at least as seem here in the lower stratosphere. For a better understanding, however, it will be necessary to consider the vertical structure, and the processes in the models, to achieve a deeper understanding of the underlying physical mechanisms behind the observed solar cycle effects.

\subsection{Volcanic aerosol}

The magnitude of total ozone and temperature changes attributed to stratospheric aerosol from volcanic eruptions is given in Figs. 14 and 15. Different from the other figures, we have not plotted two temporal standard deviations of the aerosol term $c_{A} A$, which consists of three short spikes, but rather the minimum or maximum value of this term. This minimum or maximum is usually reached in 1992 or 1993, after the 1991 eruption of Mt. Pinatubo. Thus, Figs. 14 and 15 usually give the aerosol effect occuring after the Pinatubo eruption. Following the procedure for the other parameters, Fig. 15 gives the zonally and annualy averaged results from Fig. 14.

A major effect of the Pinatubo eruption was the large warming of the stratosphere due to enhanced aerosol scattering (Robock, 2000). In a broad band around the Equator, the warming exceeded 1 to $2 \mathrm{~K}$ for temperatures at $50 \mathrm{hPa}$ (left panel, bottom row of Fig. 14; right panel of Fig. 15). In the model simulations the tropical warming is prescribed. The regression retrieves a very large tropical warming, about $4 \mathrm{~K}$, from the simulations. This is almost twice as large compared to the warming found for the NCEP reanalyses. It indicates that the volcanic warming in the tropics is prescribed too strong in the simulations (see also Fig. 1). The latitudinal variation of the warming, however, is quite similar in NCEP reanalysis and simulations.

The volcanic response of the simulations at higher latitudes is not prescribed, but generated by the model. Here the observed and simulated temperature changes are quite comparable (Fig. 15). Again, zonal symmetry is broken for the response to volcanic aerosol at high latitudes (Fig. 14). The NCEP reanalyses extend the large tropical warming over North-America, i.e. east of the Aleutian stratospheric anticyclone, whereas the simulations extend it above Sibiria, west of the Aleutian stratospheric anti-cyclone.

In the E39/C simulation, the warming covers nearly the entire polar cap. An important aspect is that the E39/C simulation produces a mid-winter stratospheric warming in the winter 1992/93. This mid-winter warming does not occur in the observations/reanalyses, or in the MAECHAM4-CHEM simulation (compare Fig. 1). To a substantial degree, stratospheric winter warmings occur at random, both in reality and in simulations. Even for constant boundary conditions, it has to be expected that some model winters will have warmings, while other years will have no warmings. Therefore, the polar warming in the E39/C simulation in Fig. 14 could be a random effect and should not be interpreted as a systematic error of the E39/C simulation. See e.g. Timmreck et al. (2004) for more information about various ECHAM-based simulations of the Pinatubo aerosol cloud.

Different from $50 \mathrm{hPa}$ temperature, the total ozone changes ascribed to volcanic aerosol look rather different between TOMS/SBUV and the simulations. In the Northern Hemisphere, there is good agreement between TOMS/SBUV and MAECHAM4-CHEM, both in the zonal means (Fig. 15), and in the geographic pattern (Fig. 14). Differences north of $60^{\circ} \mathrm{N}$ in Fig. 15 are probably not significant. Large ozone losses are found at high latitudes around $60^{\circ} \mathrm{N}$, exceeding $15 \mathrm{DU}$ in the zonal mean and $30 \mathrm{DU}$ at some longitudes. At low latitudes ozone losses are much smaller. In the Southern Hemisphere MAECHAM4CHEM simulates large ozone depletion, whereas no significant ozone depletion is found in the observations. The reason for this is unclear.

In the Northern Hemisphere, results from E39/C behave very different from TOMS/SBUV and MAECHAM4CHEM. Instead of ozone depletion, the E39/C simulation shows an ozone increase at mid to high latitudes, both in Figs. 14 and 15 (and in all seasons). This rather different result is connected to the 1992/93 mid-winter warming in the E39/C simulation. This warming also produced a positive total ozone anomaly at high latitudes in these years. Southern Hemisphere results from the E39/C simulation are in between the very large depletion simulated by MAECHAM4-CHEM, and the lack of significant depletion in the TOMS/SBUV data.

A substantial fraction of the large ozone losses at high latitudes comes from chemical destruction by chlorine, which is activated particularly at high latitudes in winter and spring on the greatly enhanced aerosol surface at low temperatures (Solomon et al., 1996; Robock, 2000; Timmreck et al., 2004). The ozone decrease at low latitudes in the models, comes from lifting of the ozone profile. Lifting is caused by the net-heating due to Pinatubo aerosol, which increased vertical ascent rates in the tropics (Stenke and Grewe, 2005). Note 
TOMS (1979-2000)

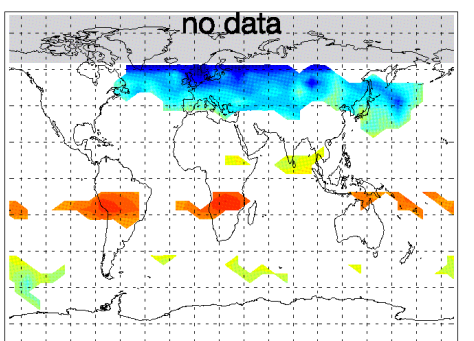

$\operatorname{NCEP}(1958-2000)$

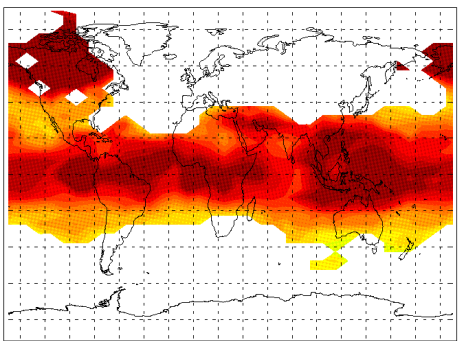

MAECHAM4-CHEM (1978-1999) aerosol, total ozone column, December/January/February

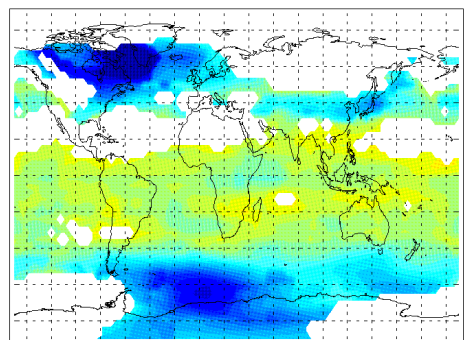

MAECHAM4-CHEM (1960-1999) aerosol, temperature at $50 \mathrm{hPa}$, December/January/February

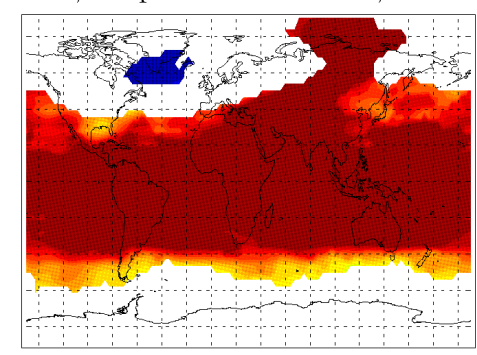

E39/C (1978-1999)

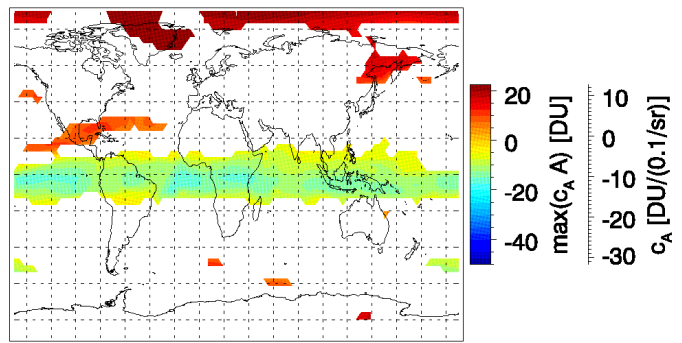

E39/C (1960-1999)

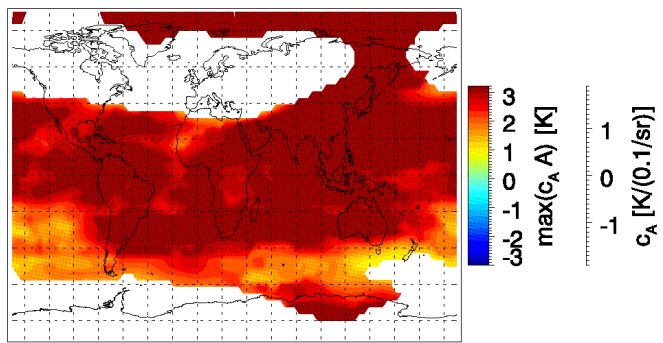

Fig. 14. Similar to Fig. 12, but for anomalies attributed to stratospheric aerosol from volcanic eruptions, mostly the Mt. Pinatubo eruption. Here the maximum positive or negative anomalies due to the aerosol term $\left(c_{A} A\right)$ are shown, not two standard deviations as in the other plots. Red and yellow colours denote positive anomalies, cyan and blue colours negative anomalies. Note that the scale for $c_{A}$ on the right is only approximate, because aerosol optical density $A$ varies with latitude.

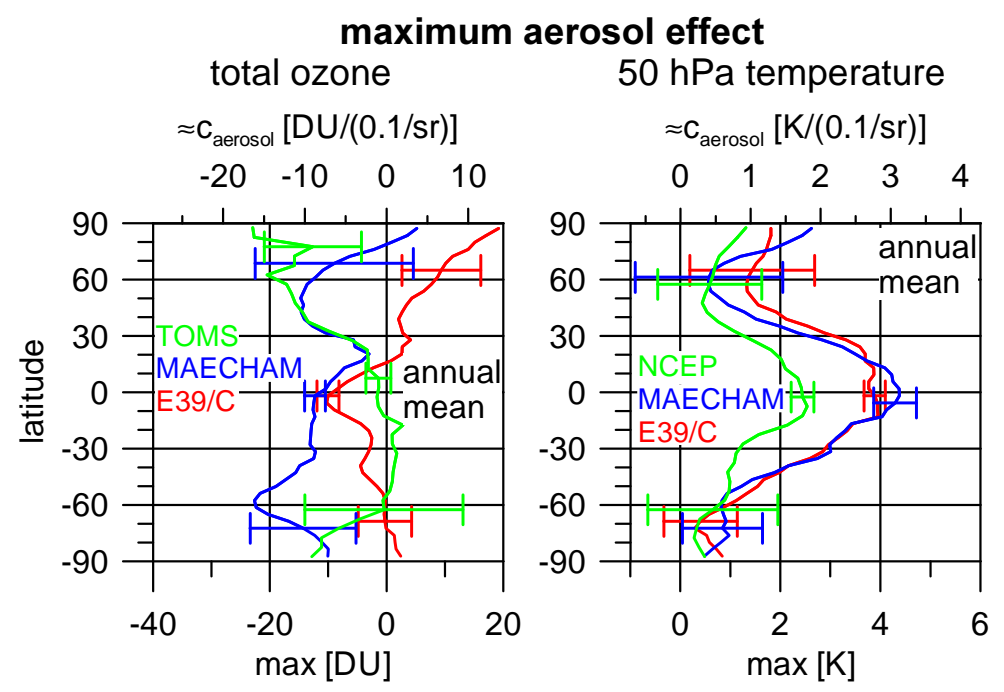

Fig. 15. Similar to Fig. 13, but showing the latitude dependence of the maximum total ozone and 50 hPa temperature variations attributed to volcanic aerosol, mostly after the Mt. Pinatubo eruption. Maximum responses from the regression were averaged over latitude and over the four seasons. The second scale, at the top, gives the approximate size of the aerosol optical density regression coefficients.

that ozone formation from high $\mathrm{SO}_{2}$ immediately after the eruption is not considered in the simulations. It might offset the ozone decrease due to lifting and might explain the very small response seen near the Equator in the TOMS data. In general, the aerosol effects from the simulations do not agree well with the observed effects.

\subsection{Polar vortex strength}

The intensity of the meridional residual Brewer-Dobson circulation in the winter stratosphere is highly correlated with the strength of the polar winter vortex (Salby and Callaghan, 2002). A strong polar winter vortex is established by high 
wind speeds in the stratospheric polar night jet. Vortex air is then isolated and the meridional circulation is weak. Stratospheric warmings have not disturbed the vortex. Little ozone and heat are transported polewards. Under these strong vortex conditions, total ozone and temperatures are low at high latitudes, but above normal at low latitudes (Labitzke and van Loon, 1999). This seesaw pattern between high and low latitudes is well known. In the Northern Hemisphere, it is also termed Arctic Oscillation or Northern Annular Mode (Thompson and Wallace, 2000). Arguably, it is the major circulation mode and extends vertically throughout the stratosphere. It is also connected to the troposphere (Baldwin and Dunkerton, 1999). In addition to weak meridional transport, a strong and cold vortex also favours the widespread formation of Polar Stratospheric Clouds, which lead to rapid chemical ozone destruction in spring - the so called "ozone hole" (Solomon, 1999). This chemical destruction further favours low total ozone and, through less ozone radiative heating, lower stratospheric temperatures. Chemical ozone destruction, thus, enhances the effect of reduced meridional transport. In order to account for this very major source of month-to-month and interannual variability in winter, zonal wind anomalies at $60^{\circ}$ latitude, $50 \mathrm{hPa}$ level, a good and easily available proxy for vortex strength, have been introduced as predictors in the regression in Eq. (1).

The size and geographical patterns of total ozone and $50 \mathrm{hPa}$ temperature fluctuations correlated with the zonal wind anomalies at $60^{\circ}$ latitude are shown in Figs. 16 and 18 for northern and southern spring, respectively. The corresponding zonal means, obtained by averaging over longitude, are shown in Figs. 17 and 19. As expected, total ozone and $50 \mathrm{hPa}$ temperatures in the polar region are inversely correlated with $60^{\circ}$ zonal wind or vortex strength. Polar ozone and temperature are much lower, when zonal wind speed is high and the vortex is strong. The polar variations are very large and exceed $50 \mathrm{DU}$ or $8 \mathrm{~K}$. At low to mid latitudes, however, total ozone or $50 \mathrm{hPa}$ temperature are slightly higher, by up to $10 \mathrm{DU}$ or $2 \mathrm{~K}$, when the vortex is strong and $60^{\circ}$ zonal wind is high. In general, the low latitude response is more pronounced for $50 \mathrm{hPa}$ temperature than for total ozone. Also, the Southern Hemisphere variations are slightly weaker than those in the Northern Hemisphere. This is related to the fact variability is lower in the Southern Hemisphere.

Whereas stratospheric warmings occur throughout winter and spring in the Northern Hemisphere, they are concentrated in a short period during vortex breakup in spring in the Southern Hemisphere. Thus, in our analysis, results for northern vortex strength in fall and winter (September/October/November, and December/January/February, all not shown) are very similar to northern spring, but variations attributed to southern vortex strength in southern fall and winter (March/April/May, and June/July/August, all not shown), are much weaker than in southern spring.

In the E39/C simulation, the southern polar vortex remains too stable for too long, and the final warming occurs too late in the year, often not before December (Dameris et al., 2005). During September and October, the E39/C simulated southern vortex does not vary enough, and does not generate enough ozone and temperature variations for a significant signal. This late breakup is related to the large cold pole bias of the southern vortex in the E39/C simulation (Austin et al., 2003). To account for this later breakup, we have plotted December/January/February, instead of September/October/November, in Figs. 18 and 19, for the E39/C model.

Apart from this temporal shift for E39/C, both model simulations and the observations show similar patterns for the large negative polar response, and for the small positive response at low latitudes. The zonally asymmetric structure at high latitudes in Fig. 16 is matched well by MAECHAM4CHEM, slightly less well by E39/C. In the Northern Hemisphere, however, the magnitude of the polar response is substantially too large in both simulations (Fig. 17). We attribute this to the cold pole bias of both simulations (Austin et al., 2003), which for periods with a stable vortex results in too low temperature and too low total ozone. Since warm period temperatures are matched well by the simulations, the swing between warm weak and cold strong vortex episodes comes out too large in the simulations. In contrast, in the Southern Hemisphere, the modelled polar response is slightly smaller than observed. Likely this is related to the cold bias of the models as well, which in the Southern Hemisphere results in smaller variability and a very short time period during which the vortex breaks up. This reduces the width of the probability distribution between warm and cold episodes and results in a smaller average swing between the two. Apart from the mentioned problems, which appear to be related to cold pole bias, both models quite reasonably simulate the very large total ozone and $50 \mathrm{hPa}$ temperature fluctuations associated with variations of the intensity of the polar winter vortices.

An interesting aspect in Fig. 18 is the (blue) low $50 \mathrm{hPa}$ temperature pattern above Northern Canada that is correlated with a strong southern vortex in September/October/November. It is found both in NCEP reanalyses and MAECHAM4-CHEM simulation. It might point to an interhemispheric connection, by which the ending southern polar vortex is connected with the beginning northern polar vortex.

\subsection{Tropospheric temperature}

Dobson et al. (1929) already realized that total column ozone is changing during the passage of tropospheric weather systems. This connection is relevant for interannual and longer time-scales as well (Steinbrecht et al., 1998). To account for it, tropospheric temperature (at $400 \mathrm{hPa}$ ), highly correlated with other parameters of tropospheric weather such as tropopause height, or temperature at other tropospheric levels, was included in the predictors of Eq. (1). The size of the corresponding total ozone and $50 \mathrm{hPa}$ (lower strato- 
total ozone column anomalies correlated with zonal wind anomalies at $60^{\circ} \mathrm{N}, 50 \mathrm{hPa}$, March/April/May

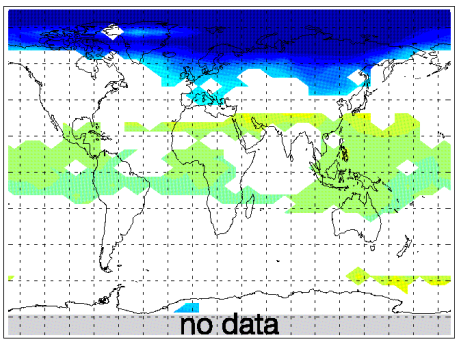

NCEP (1958-2000)

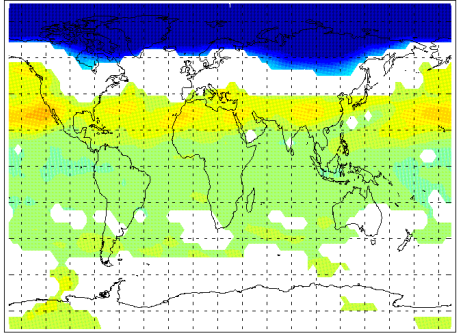

MAECHAM4-CHEM (1960-1999)

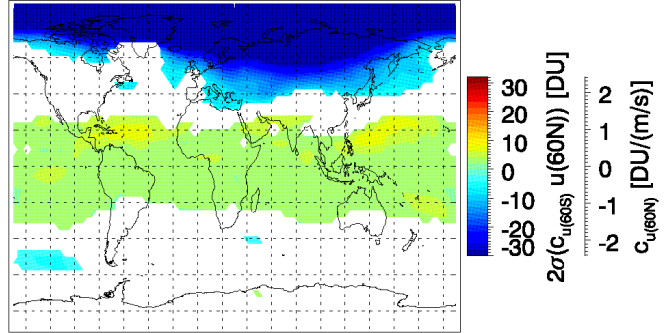

E39/C (1960-1999)

temperature anomalies at $50 \mathrm{hPa}$ correlated with zonal wind anomalies at $60^{\circ} \mathrm{N}, 50 \mathrm{hPa}$, March/April/May
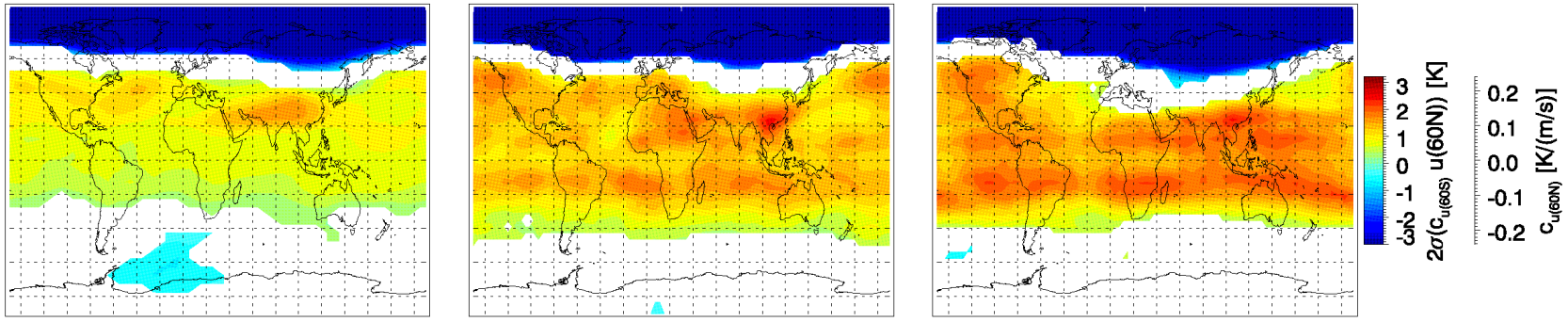

Fig. 16. Same as Fig. 12, but showing the size $(2 \sigma)$ of anomalies related to Arctic polar vortex strength, for northern spring (March/April/May). Polar vortex strength is represented by zonal wind anomalies at $60^{\circ} \mathrm{N}, 50 \mathrm{hPa}$. The second scales on the right give the size of the regression coefficient $c_{u}\left(60^{\circ} \mathrm{N}\right)$.
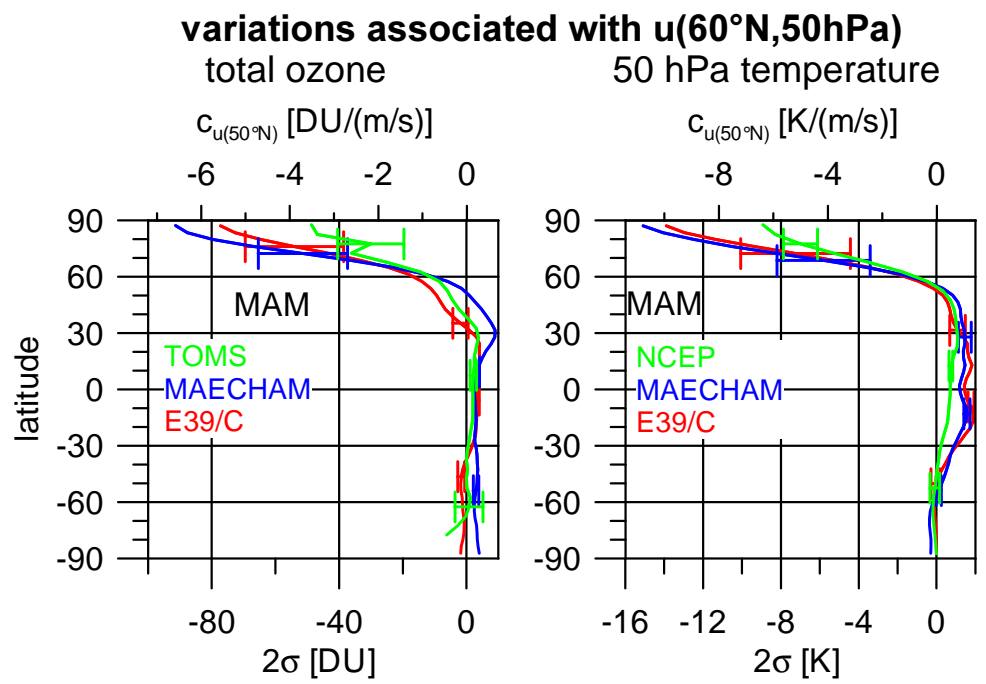

Fig. 17. Similar to Fig. 13, but showing the latitude dependence of the size of total ozone and $50 \mathrm{hPa}$ temperature variations associated with variations in zonal wind at $60^{\circ} \mathrm{N}, 50 \mathrm{hPa}$. Results are for March/April/May only. The second scale, at the top, gives the approximate size of the regression coefficient $c_{u}\left(60^{\circ} \mathrm{N}\right)$.

spheric) temperature variations is given in Figs. 20 and 21. Nearly over the entire globe, high tropospheric temperature goes hand in hand with low total ozone and low temperature in the lower stratosphere. The corresponding variations are quite large and exceed $10 \mathrm{DU}$ or $1 \mathrm{~K}$ at latitudes polewards of $30^{\circ}$ to $40^{\circ}$. In general, the seasonal dependence of these pattern is weak (not shown), although the largest amplitudes are found in spring, in the respective hemisphere. The extratropical variation is generally larger in the Northern Hemisphere than in the Southern Hemisphere. In the tropics, total ozone and lower stratospheric temperature variations correlated with $400 \mathrm{hPa}$ temperature are smaller than 
TOMS (1979-2000)

MAECHAM4-CHEM (1978-1999)

total ozone column anomalies correlated with zonal wind anomalies at $60^{\circ} \mathrm{S}, 50 \mathrm{hPa}$, Southern spring

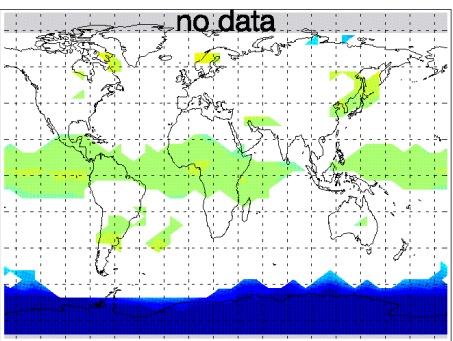

NCEP (1958-2000)

MAECHAM4-CHEM (1960-1999)

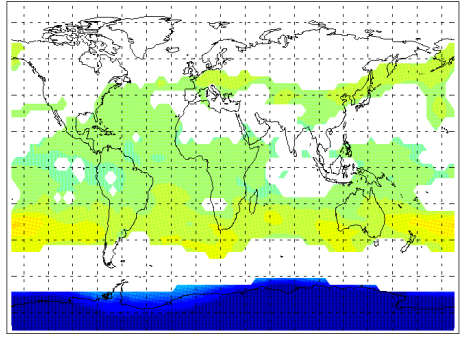

at $50 \mathrm{hPa}$ correlated with zonal wind

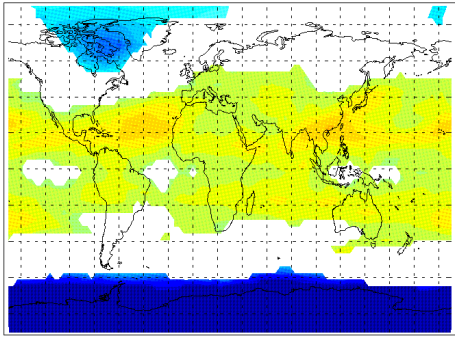

$\mathrm{E} 39 / \mathrm{C}(1978-1999)$

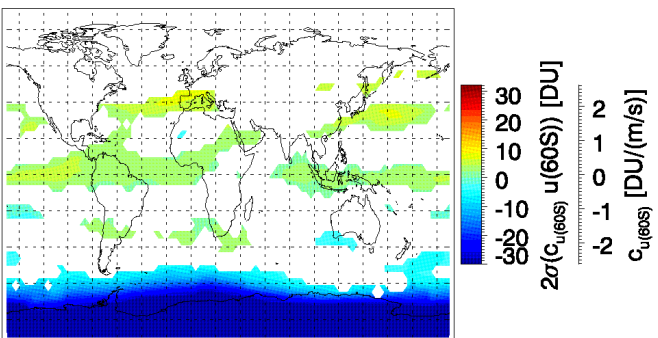

E39/C (1960-1999)

omalies at $60^{\circ} \mathrm{S}, 50 \mathrm{hPa}$, Southern spring

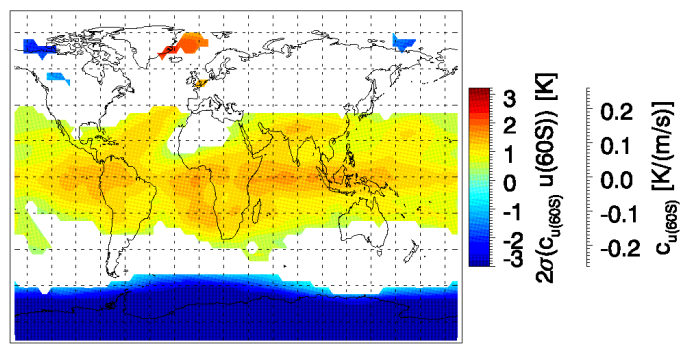

Fig. 18. Same as Fig. 16, but for Antarctic polar vortex strength, and southern spring. For observations and MAECHAM4-CHEM simulation September/October/November are plotted. Because of the late breakup of the Antarctic vortex in the E39/C simulation, December/January/February is plotted for the E39/C model. Antarctic polar vortex strength is represented by zonal wind anomalies at $60^{\circ} \mathrm{S}$,

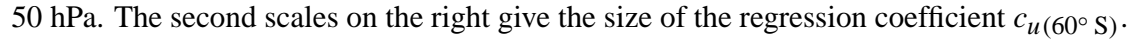
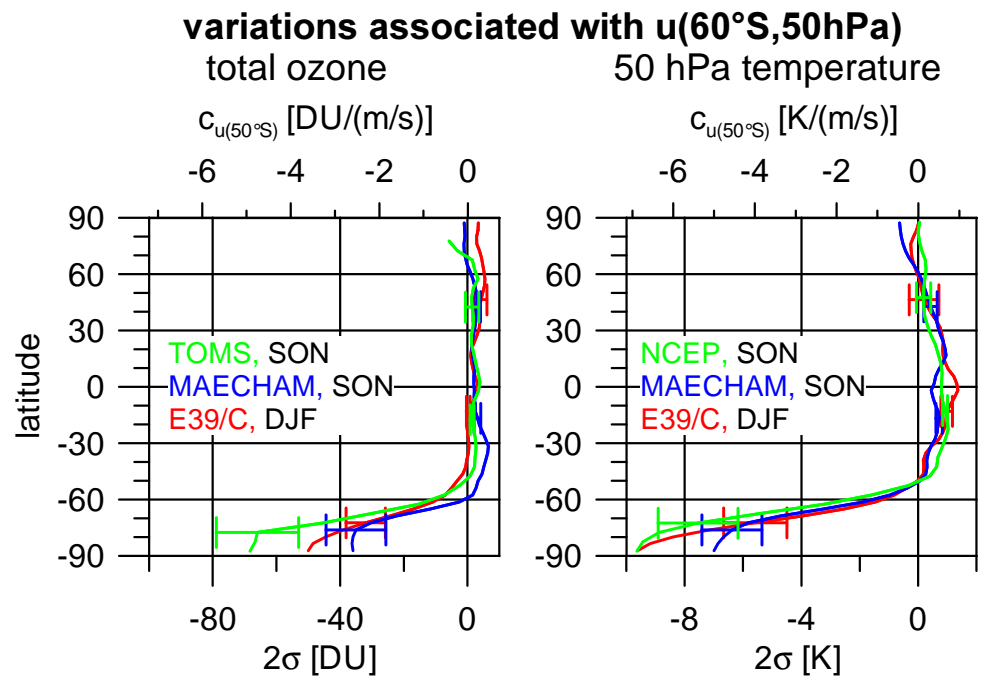

Fig. 19. Same as Fig. 17, but for zonal wind at $60^{\circ} \mathrm{S}, 50 \mathrm{hPa}$. For TOMS/SBUV, NCEP, and MAECHAM4-CHEM September/October/November results were plotted. Due to the prolonged vortex life-time in E39/C we plotted December/January/February results for this model.

at higher latitudes. They typically amount to less than $10 \mathrm{DU}$ or $1 \mathrm{~K}$. The geographical patterns look similar for total ozone and temperature. Although MAECHAM4-CHEM shows a larger total ozone response, observations and model simulations generally present a very similar picture.
This strong negative correlation between tropospheric temperature and lower stratospheric ozone and temperature can be explained by up- and downward motions in the lower stratosphere, which compensate opposite vertical motions in the troposphere (Steinbrecht et al., 1998; Labitzke and van Loon, 1999). In a tropospheric high pressure system, sink- 

total ozone column anomalies correlated with temperature anomalies at $400 \mathrm{hPa}$, March/April/May

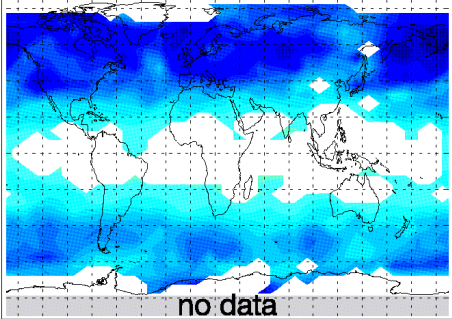

NCEP (1958-2000)

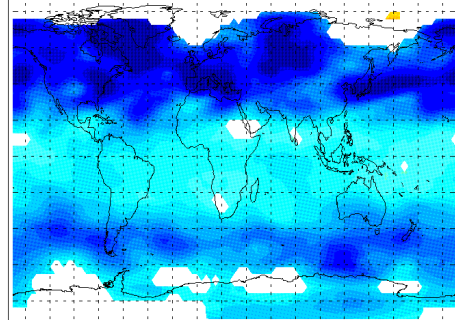

MAECHAM4-CHEM (1960-1999)

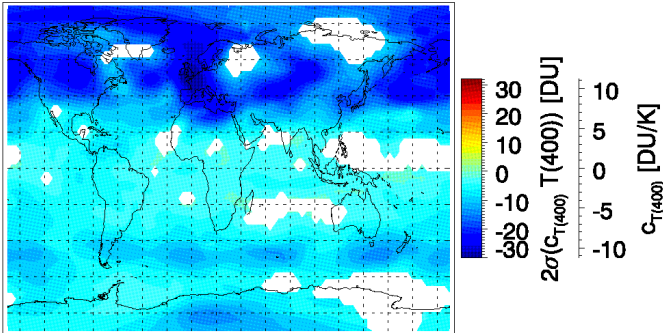

E39/C (1960-1999) temperature anomalies at $50 \mathrm{hPa}$ correlated with temperature anomalies at $400 \mathrm{hPa}$, March/April/May
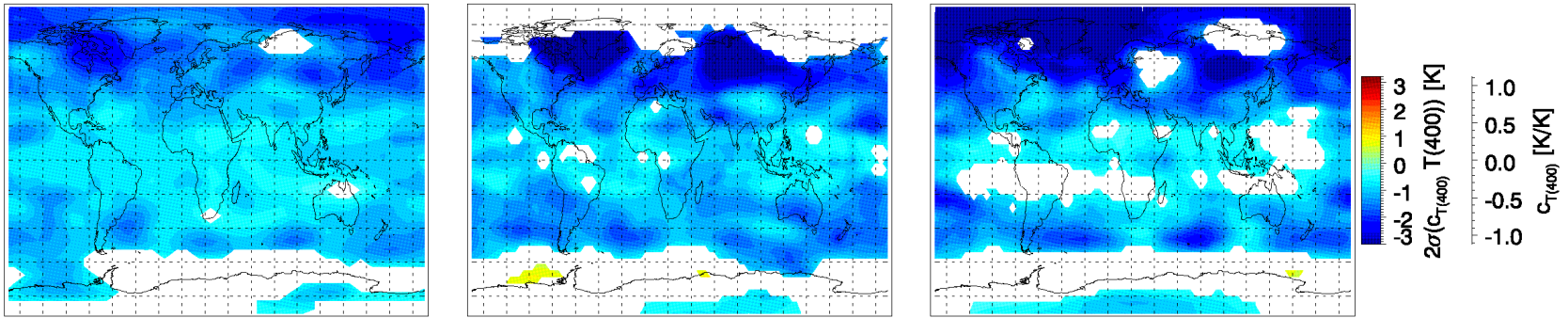

Fig. 20. Similar to Fig. 18, but showing the size $(2 \sigma)$ of stratospheric ozone and $50 \mathrm{hPa}$ temperature anomalies attributed to tropospheric temperature anomalies at $400 \mathrm{hPa}$ (term $\left.c_{T(400)} T(400)\right)$. The second scales, on the right, only give the approximate size of the regression coefficient $c_{T(400)}$.
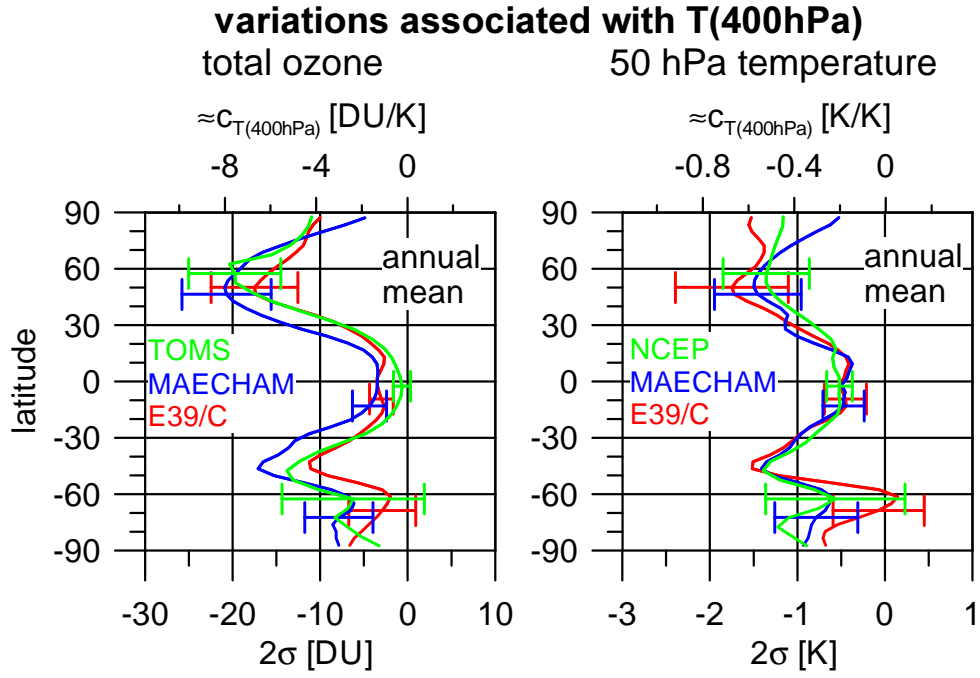

Fig. 21. Similar to Fig. 13, but showing the latitude dependence of the size of total ozone and $50 \mathrm{hPa}$ temperature variations associated with anomalies of tropospheric temperature at $400 \mathrm{hPa}$. Annual mean results are shown. The second scale, at the top, gives the approximate size of the regression coefficient $c_{T(400)}$.

ing air in the troposphere leads to adiabatic warming there. The tropopause and air in the lower stratosphere rise. This results in adiabatic cooling in the lower stratosphere and moves ozone poor air up. Total ozone decreases. A tropospheric low pressure system has vertical motions in the opposite direction, and consequently a cold troposphere and a warm, ozone rich lower stratosphere with high total ozone. These vertical motions go hand in hand with horizontal advection, e.g. of ozone poor air from low latitudes, or of ozone rich air from high latitudes in the lower stratosphere (Salby and Callaghan, 1993; Koch et al., 2002). A typical low pressure system advects ozone poor low-latitude air above its tropo- 
spheric warm sector, where the tropopause is high, and advects ozone rich high-latitude air above its tropospheric cold sector, where the tropopause is low. Salby and Callaghan (1993) estimate that vertical motions account for about two thirds, and horizontal advection for about one third of the total ozone fluctuations. Note that increased/decreased radiative heating by more/less ozone also tends to give a positive correlation between total ozone and lower stratospheric temperature on longer time-scales (Ramaswamy et al., 2001).

\subsection{El Niño - Southern Oscillation}

The El Niño - Southern Oscillation (ENSO) phenomenon of the tropical Pacific is one of the major modes of variance for sea-surface temperature and tropospheric temperature in the tropics. The corresponding Southern Oscillation Index is plotted at the very bottom of Fig. 1. This index is positive during La Niña cold phases and negative during El Niño warm phases.

To estimate the ENSO effect, the regression was done without including $400 \mathrm{hPa}$ temperature as a predictor in Eq. (1). Note, however, that outside of the tropics, results would be very similar even if $T$ (400) would be included (see Steinbrecht et al., 2003). Figure 22 shows the typical size of total ozone and temperature changes between La Niñas and El Niños for northern winter (December/January/February). The zonal mean annual mean response in shown in Fig. 23.

Throughout much of the tropics, especially above the Eastern Pacific, total ozone and lower stratospheric temperature at $50 \mathrm{hPa}$ are higher during La Niña event, when sea surface and tropospheric temperature are colder. Over the Pacific and in northern winter, the difference can reach 5 to $15 \mathrm{DU}$, or 0.5 to $2 \mathrm{~K}$, for total ozone and $50 \mathrm{hPa}$ temperature respectively (Fig. 22). The zonal mean signal is smaller and typically less than $5 \mathrm{DU}$ or $0.5 \mathrm{~K}$ in the tropics (Fig. 23). These stratospheric changes have the opposite sign to the tropospheric variation, which can exceed $3 \mathrm{~K}$ in the tropical eastern $\mathrm{Pa}$ cific, the region of the largest effect. Northern fall and spring (September/October/November, and March/April/May, both not shown) exhibit similar, but slightly weaker and less significant variations.

In the extratropics, the ENSO response has the opposite sign compared to the tropics. Total ozone and $50 \mathrm{hPa}$ temperature are generally lower during La Niña, and higher during El Niño. In the zonal mean annual mean, the largest and most significant response is seen around $40^{\circ} \mathrm{N}$, where it reaches up to $-5 \mathrm{DU}$ or $-0.5 \mathrm{~K}$. A slightly smaller signal is seen around $30^{\circ} \mathrm{S}$ in the Southern Hemisphere. In tropics and mid-latitudes observations and simulations give a similar picture.

Polewards of $60^{\circ}$ longitudinal variations become important. The zonal mean annual mean results in Fig. 23 differ between models and observations. Response and differences may not always be significant. However, a significant zonally asymmetric feature, present in observations and simulations in Fig. 22, are the substantially lower $50 \mathrm{hPa}$ temperatures during La Niña over Eastern Asia or over the Aleutians/North America (-3 K, blue region in Fig. 22). They are accompanied, in NCEP reanalysis and MAECHAM4-CHEM simulation, by warmer $50 \mathrm{hPa}$ temperatures and higher total ozone above Europe (up to $+3 \mathrm{~K}$, or +10 DU, red and yellow region). Compared to the observations, the negative temperature anomaly over Eastern Asia is shifted east, towards the Aleutians or North America, in the models. A corresponding negative (blue) total ozone anomaly does appear in both simulations, but not in the TOMS/SBUV data (or is not significant there). The stratospheric feature is related to a tropospheric dipole feature of positive $400 \mathrm{hPa}$ temperature anomalies above the Aleutians and negative anomalies above North America (not shown), which is found both in observations and simulations in the troposphere.

These ENSO anomaly patterns near the Aleutians indicate changes in the Aleutian tropospheric cyclone and stratospheric anti-cyclone that are correlated with ENSO. A generally stronger and more stable Arctic polar vortex during La Niña has been reported, e.g. in Labitzke and van Loon (1999). This is consistent with our findings.

\section{Conclusions}

Multiple linear regression can be used to quantify major modes of the interannual variation of total ozone and lower stratospheric temperature, both from long-term observations/reanalysis, and from new 1960 to 1999 simulations with the MAECHAM4-CHEM and E39/C chemistry climate models and realistic forcings. Comparison of the derived interannual variation patterns extends the model validation from a simple validation of climatological means and variances towards are comparison of several important modes of interannual variations.

For a large part of the globe, $60 \%$ or more of the variance can be explained by assuming that anomalies of total ozone, or temperature at $50 \mathrm{hPa}$, can be described as a simple linear superposition of predictors accounting for trend, QBO, solar cycle, polar vortex strength, stratospheric aerosol loading, tropospheric temperature and ENSO. In large bands above the mid-latitude jet-streams, however, only 20 to $40 \%$ of the variance can be accounted for in this way.

For the different explanatory variables, total ozone and $50 \mathrm{hPa}$ temperature fluctuations range from less than $5 \mathrm{DU}$ or $0.5 \mathrm{~K}$ (two standard deviations of the corresponding time series term in Eq. (1)) to almost $100 \mathrm{DU}$ or $15 \mathrm{~K}$, respectively. Substantial changes come from the linear trend term, up to $-10 \mathrm{DU} /$ decade at high northern latitudes, up to $-40 \mathrm{DU} /$ decade at high southern latitudes, and around $-0.7 \mathrm{~K} /$ decade over much of the globe. Ozone trends are generally overestimated by the MAECHAM4-CHEM simulation, but slightly underestimated by the E39/C simulation. The true long-term decline in winter and spring above the 


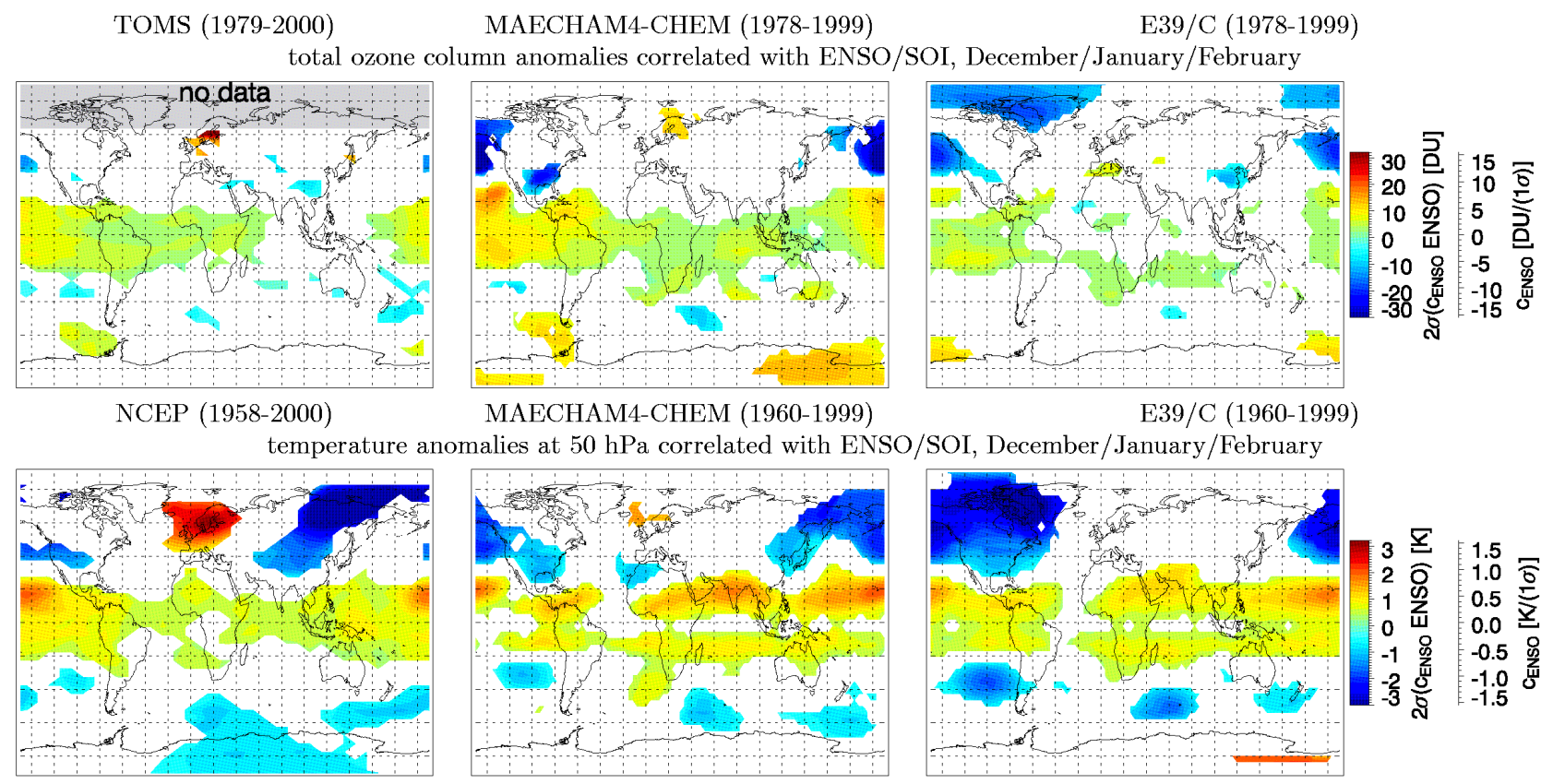

Fig. 22. Same as Fig. 20, but showing the size $(2 \sigma)$ of anomalies correlated with the El Niño Southern-Oscillation Index. These results where obtained without using $400 \mathrm{hPa}$ temperature as an explanatory variable in Eq. (1).

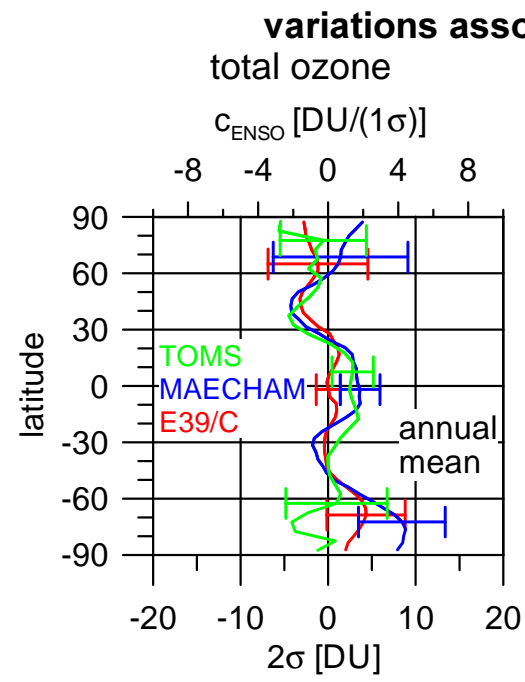

\section{$50 \mathrm{hPa}$ temperature}

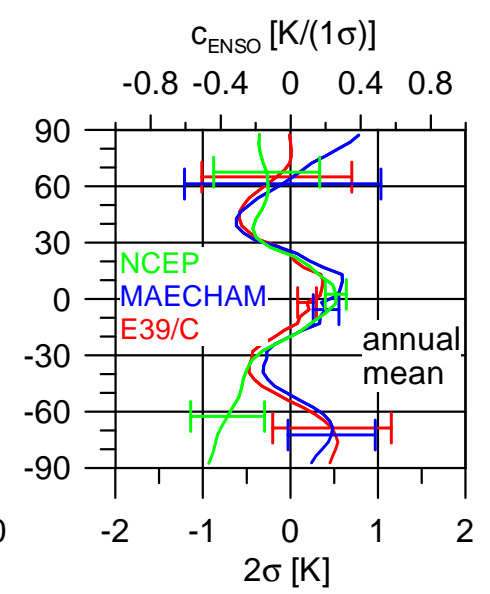

Fig. 23. Similar to Fig. 21, but showing the latitude dependence of the size of total ozone and $50 \mathrm{hPa}$ temperature variations correlated with the El Niño Southern-Oscillation Index Annual mean results are shown. The second scale, at the top, gives the approximate size of the regression coefficient $c_{E N S O}$. These results where obtained without using $400 \mathrm{hPa}$ temperature as an explanatory variable in Eq. (1).

Arctic may be underestimated by a lack of TOMS/SBUV observations in winter, particularly in the cold 1990s. Large variations come from terms related to polar vortex strength, more than $40 \mathrm{DU}$ or $8 \mathrm{~K}$, from tropospheric meteorology, up to $20 \mathrm{DU}$ or $2 \mathrm{~K}$, or from the QBO, up to $10 \mathrm{DU}$ or $1.5 \mathrm{~K}$. The 11-year solar cycle, generally less than $10 \mathrm{DU}$ or $0.5 \mathrm{~K}$, or ENSO, up to $10 \mathrm{DU}$ or $1 \mathrm{~K}$, are somewhat smaller contributors.
Magnitude and geographical patterns of the changes correlated with most predictors are similar for observations and simulations. Despite its restriction to altitudes below $30 \mathrm{~km}, \mathrm{E} 39 / \mathrm{C}$ reproduces many aspects the observed variations. Due to the polar cold bias of the model, however, the polar vortex breakup is delayed and northern mid-latitude ozone trends are underestimated. As expected from its extended altitude range up to $80 \mathrm{~km}$, and its better representa- 
tion of upper stratospheric and mesospheric processes like gravity waves, the MAECHAM4-CHEM simulation usually gives better agreement with the observations, especially for those variability patterns which include upper stratospheric/mesospheric processes. Examples are the link between SH polar vortex strength and total ozone variability, or the QBO. On the other hand, both models represent vortex strength, solar cycle, or tropospheric influence patterns almost equally well.

A large but sporadic effect results from stratospheric aerosol, which has lead to warming up to $3 \mathrm{~K}$ at low latitudes and to ozone depletion up to -30 DU at high latitudes after the 1991 Pinatubo eruption. The aerosol effect is more difficult to isolate. The model simulations prescribe too much warming, by up to $4 \mathrm{~K}$, in the tropics, and give different aerosol effects on total ozone in the extratropics. MAECHAM4-CHEM simulates ozone depletion at southern mid-latitudes that is not seen in the observations, whereas E39/C produces a stratospheric winter warming that is not seen in observations or MAECHAM4-CHEM simulation. Note however, that both observations and the single simulations are just one realisation of many possible evolution. This makes the comparison of single events like volcanic eruptions problematic.

At low latitudes, patterns are mostly zonally symmetric. At high latitudes, however, zonal symmetry is often broken. High latitude patterns seem to be wave-like with a change in intensity and/or location of the Aleutian stratospheric anti-cyclone in the Northern Hemisphere, or the Australian anti-cyclone in the Southern Hemisphere. While the simulations often reproduce the magnitude of these zonally non-symmetric patterns, they usually shift their location to different longitudes.

For the present study we are not adressing connections between polar vortex strength, 11-year solar cycle, phase of the QBO, and possibly El Niño (Labitzke et al., 2002; Ruzmaikin and Feynman, 2002; Lee and Smith, 2003). We speculate that the zonally non-symmetric nature of the high-latitude atmosphere is essential for these connections, and that they might work through the Aleutian and Australian stratospheric anticyclones, and, possibly, their corresponding tropospheric cyclones. In the regression according to Eq. (1), the zonal wind anomalies $u(60 N)$ and $u(60 S)$ to a large degree account for the net variations correlated with polar vortex strength, due to whatever factor may be contributing to polar vortex strength. Still, very similar results are found, when only solar cycle, QBO and linear trend are allowed as explanatory variables in Eq. (1), and the other explanatory variables are not used. Steinbrecht et al. (2003) showed results for the solar cycle effect during QBO westerly and QBO easterly phases, but the differences were not major. Similar results are also found in the model simulations, but are not shown here. Nevertheless, the whole issue is more complex, and merits a separate investigation in the future.
Apart from the mentioned differences, both model simulations give a generally good representation of the variation of the stratosphere over the last 40 years. Unfortunately they both end in 1999. It will be very worthwile to extend these simulations to the present and into the future. Additional simulations, e.g. with individual influences switched on or off, should also bring valuable contributions to questions regarding the expected recovery of the stratospheric ozone layer, effects of climate change on stratosphere and troposphere, and to our understanding of the connections between these issues and between these different parts of our atmosphere.

Acknowledgements. This investigation was made possible by the KODYACS project, funded under AF02000 (http://www.afo2000.de) by the German Ministry for Education and Research, grant ATF43. Very useful comments by two anonymous reviewers have helped to focus and improve the manuscript.

Edited by: V. Fomichev

\section{References}

Austin, J., Shindell, D., Beagley, S. R., Brühl, C., Dameris, M., Manzini, E., Nagashima, T., Newman, P., Pawson, S., Pitari, G., Rozanov, E., Schnadt, C., and Shepherd, T. G.: Uncertainties and assessments of chemistry-climate models of the stratosphere, Atmos. Chem. Phys., 3, 1-27, 2003,

SRef-ID: 1680-7324/acp/2003-3-1.

Baldwin, M. P., Gray, L. J., Dunkerton, T. J., Hamilton, K., Haynes, P. H., Randel, W. J., Holton, J. R., Alexander, M. J., Hirota, I., Horinouchi, T., Jones, D. B. A., Kinnersley, J. S., Marquardt, C., and Takahashi, M.: The Quasi-Biennial Oscillation, Rev. Geophys., 39, 179-229, 2001.

Baldwin, M. P. and Dunkerton, T. J.: Propagation of the Arctic Oscillation from the stratosphere to the troposphere, J. Geophys. Res., 104, 30 937-30 946, 1999.

Callaghan, P. F. and Salby, M. L.: Three-Dimensionality and forcing of the Brewer-Dobson circulation, J. Atmos. Sci., 59, 976991, 2002.

Dameris, M., Grewe, V., Ponater, M., Deckert, R., Eyring, V., Mager, F., Matthes, S., Schnadt, C., Stenke, A., Steil, B., Brühl, C., and Giorgetta, M. A.: Long-term changes and variability in a transient simulation with a chemistry-climate model employing realistic forcing, Atmos. Chem. Phys., 5, 2121-2145, 2005,

SRef-ID: 1680-7324/acp/2005-5-2121.

Dobson, G. M. B., Harrison, D. N., and Lawrence, J.: Measurements of the amount of ozone in the earth's atmosphere and its relation to other geophysical conditions, III, Proc. Roy. Soc. London A, 122, 456-486, 1929.

Fioletev, V. E., Bodeker, G. E., Miller, A. J., McPeters, R. D., and Stolarski, R.: Global and zonal total ozone variations estimated from ground-based and satellite measurements: 1964-2000, J. Geophys. Res., 107, 4647, doi:10.1029/2001JD001350, 2002.

Giorgetta, M. A. and Bengtsson, L.: The potential role of the quasibiennial oscillation in the stratosphere-troposphere exchange as 
found in water vapour in general circulation model experiments, J. Geophys. Res., 104, 6003-6019, 1999.

Giorgetta, M. A., Manzini, E., and Roeckner, E.:, Forcing of the quasi-biennial oscillation from a broad spectrum of atmospheric waves, Geophys. Res. Lett., 29(D8), 1245, doi:10.1029/2002GL014756, 2002.

Grewe, V., Brunner, D., Dameris, M., Grenfell, J. L., Hein, R., Shindell, D., and Staehelin, J.: Origin and variability of upper tropospheric nitrogen oxides and ozone at northern midlatitudes, Atmos. Environ., 35, 3421-3433, 2001.

Grewe, V., Dameris, M., Fichter, C., and Sausen, R.: Impact of aircraft $\mathrm{NO}_{\mathrm{x}}$ emissions. Part 1: Interactively coupled climatechemistry simulations and sensitivities to climate-chemistry feedback, lightning and model resolution, Meteorol. Z., 3, 177186, 2002.

Hein, R., Dameris, M., Schnadt, C., Land, C., Grewe, V., Köhler, I., Ponater, M., Sausen, R., Steil, B., Landgraf, J., and Brühl, C.: Results of an interactively coupled atmospheric chemistry general circulation model: Comparison with observations, Ann. Geophys., 19, 435-457, 2001,

\section{SRef-ID: 1432-0576/ag/2001-19-435.}

Hood, L. L.: The solar cycle variation of total ozone: Dynamical forcing in the lower stratosphere, J. Geophys. Res., 102, 13551370, 1997.

Hurrell, J. W., and Trenberth, K. E.: Difficulties in Obtaining Reliable Temperature Trends: Reconciling the Surface and Satellite Microwave Sounding Unit Records, J. Clim., 11, 945-967, 1998.

IPCC - Intergovernmental Panel on Climate Change: Climate Change 2001: The Scientific Basis, Contribution of Working Group I to the Third Assessment, Report of the Intergovernmental Panel on Climate Change (IPCC), edited by: Houghton, J. T., Ding, Y., Griggs, D. J., Noguer, M., van der Linden, P. J., and Xiaosu, D., Cambridge University Press, Cambridge, UK, 944 pp., 2001.

Kistler, R., Kalnay, E., Collins, W., Saha, S., White, G., Woollen, J., Chelliah, M., Ebisuzaki, W., Kanamitsu, M., Kousky, V., van den Dool, H., Jenne, R., and Fiorino, M.: The NCEP-NCAR 50-Year Reanalysis: Monthly Means, CD-ROM and Documentation, Bull. Am. Met. Soc., 82, 247-267, http://www.cpc.ncep. noaa.gov/products/wesley/reanalysis.html, 2001.

Koch, G., Wernli, H., Staehelin, J., and Peter, T.: A Lagrangian analysis of stratospheric ozone variability and long-term trends above Payerne (Switzerland) during 1970-2001, J. Geophys. Res., 107, 4373, doi:10.1029/2001JD001550, 2002.

Labitzke, K. and van Loon, H.: The stratosphere: phenomena, history, and relevance, Springer Verlag, Berlin, 197 pp., 1999.

Labitzke, K., Austin, J., Butchart, N., Knight, J., Takahashi, M., Nakamoto, M., Nagashima, T., Haigh, J., and Williams, V.: The global signal of the 11-year solar cycle in the stratosphere: observations and models, J. Atmos. Solar-Terr. Phys., 64, 203-210, 2002

Lean, J. L., Rottman, G. J., Kyle, H. L., Woods, T. N., Hickey, J. R., and Puga, L. C.: Detection and parameterization of variations in solar mid- and near-ultraviolet radiation (200-400 nm), J. Geophys. Res., 102, 29 939-29956, 1997.

Lee, H. and Smith, A. K.: Simulation of the combined effects of solar cycle, quasi-biennial oscillation, and volcanic forcing on stratospheric ozone changes in recent decades, J. Geophys. Res., 108(D2), 4049, doi:10.1029/2001JD001503, 2003.
Manzini, E., McFarlane, N. A., and McLandress, C.: Impact of the Doppler Spread Parameterization on the simulation of the middle atmosphere circulation using the MA/ECHAM4 general circulation model, J. Geophys. Res., 102, 25 751-25 762, 1997.

Manzini, E. and McFarlane, N. A.: The effect of varying the source spectrum of a gravity wave parameterization in a middle atmosphere general circulation model, J. Geophys. Res., 103, 31 523$31539,1998$.

Manzini, E., Steil, B., Brühl, C., Giorgetta, M. A., and Krüger, K.: A new interactive chemistry climate model: 2 . Sensitivity of the middle atmosphere to ozone depletion and increase in greenhouse gases and implications for recent stratospheric cooling, J. Geophys. Res., 108(D14), 4429, doi:10.1029/2002JD002977, 2003.

Matthes, K., Langematz, U. , Gray, L. L., Kodera, K., and Labitzke, K.: Improved 11-year solar signal in the Freie Universitaet Berlin Climate Middle Atmosphere Model (FUB-CMAM), J. Geophys. Res., 109, D06101, doi:10.1029/2003JD004012, 2004.

Newchurch, M. J., Yang, E.-S., Cunnold, D. M., Reinsel, G. C., Zawodny, J. M., and Russell III, J. M.: Evidence for slowdown in stratospheric ozone loss: First stage of ozone recovery, J. Geophys. Res., 108(D16), 4507, doi:10.1029/2003JD003471, 2003.

Ramaswamy, V., Chanin, M. L., Angell, J., Barnett, J., Gaffen, D., Gelman, M., Keckhut, P., Koshelkov, Y., Labitzke, K., Lin, J. J. R., O’Neil, A., Nash, J., Randel, W., Rood, R., Shiotani, M., Swinbank, R., and Shine, K.: Stratospheric temperature trends: observations and model simulations, Rev. Geophys., 39, 71-122, 2001. See also http://www.atmosp.physics.utoronto.ca/SPARC/ News18/18_Ramaswamy.html.

Rasch, P. J. and Lawrence, M. G.: Recent developments in transport methods at NCAR, in: Proceedings of the MPI workshop on conservative transport methods, Report No. 265, edited by: Machenhauer, B., 93 pp., Max Planck Institute for Meteorology, Hamburg, Germany, 1998.

Rayner, N. A., Parker, D. E., Horton, E. B., Folland, C. K., Alexander, L. V., Rowell, D. P., Kent, E. C., and Kaplan, A.: Global analyses of sea surface temperature, sea ice, and night marine air temperature since the late nineteenth century, J. Geophys. Res., 108(D14), 4407, doi:10.1029/2002JD002670, 2003.

Reinsel G. C., Miller, A. J., Weatherhead, E. C. , Flynn, L. E., Nagatani, R. M., Tiao, G. C., and Wuebbles, D. J.: Trend analysis of total ozone data for turnaround and dynamical contributions, J. Geophys. Res., 110, D16306, doi:10.1029/2004JD004662, 2005.

Rinsland, C. P., Mahieu, E., Zander, R., Jones, N. B., Chipperfield, M. P., Goldman, A., Anderson, J., Russell III, J. M., Demoulin, P., Notholt, J., Toon, G. C., Blavier, J.-F., Sen, B., Sussmann, R., Wood, S. W., Meier, A., Griffith, D. W. T., Chiou, L. S., Murcray, F. J., Stephen, T. M., Hase, F., Mikuteit, S., Schulz, A., and Blumenstock, T.: Long-term trends of inorganic chlorine from ground-based infrared solar spectra: Past increases and evidence for stabilization, J. Geophys. Res., 108(D8), 4252, doi:10.1029/2002JD003001, 2003.

Robock, A.: Volcanic eruptions and climate, Rev. Geophys., 38, 191-219, 2000.

Roeckner, E., Arpe, L., Bengtsson, L., Christoph, M., Claussen, M., Dümenil, L., Esch, M., Giorgetta, M. A., Schlese, U., and Schulzweida, U.: The atmospheric general circulation model ECHAM-4: Model description and simulation of present-day climate, Rep. No. 218, MPI-Meteorologie, Hamburg, Germany, 90 
pp., 1996.

Ruzmaikin, A. and Feynman, J.: Solar influence on a major mode of atmospheric variability, J. Geophys. Res., 107(D14), doi:10.1029/2001JD001239, 2002.

Salby, M. L. and Callaghan, P. F.: Fluctuations of total ozone and their relationship to stratospheric air motions, J. Geophys. Res., 98, 2715-2727, 1993.

Salby, M. L. and Callaghan, P. F.: Interannual changes of the stratospheric circulation: relationship to ozone and tropospheric structure, J. Clim., 24, 3673-3685, 2002.

Santer, B. D., Wigley, T. M. L., Sausen, R. , Meehl, G. A. , Taylor, K. E. , Ammann, C., Arblaster, J., Washington, W. M., Boyle, J. S., and Brüggemann, W.: Response to Comment on "Contributions of Anthropogenic and Natural Forcing to Recent Tropopause Height Changes”, Science, 303, 1771, 2004.

Schnadt, C., Dameris, M., Ponater, M., Hein, R., Grewe, V., and Steil, B.: Interaction of atmospheric chemistry and climate and its impact on stratospheric ozone, Clim. Dyn., 18, 501-517, 2002

Schnadt, C. and Dameris, M.: Relationship between North Atlantic Oscillation changes and stratospheric ozone recovery in the Northern Hemisphere in a chemistry-climate model, Geophys. Res. Lett., 30(9), 1487, doi:10.1029/2003GL017006, 2003.

Shine, K. P., Bourqui, M. S., Forster, P. M. F., Hare, S. H. E., Langematz, U., Braesicke, P., Grewe, V., Ponater, M., Schnadt, C., Smith, C. A., Haigh, J. D., Austin, J., Butchart, N., Shindell, D. T., Randel, W. J., Nagashima, T., Portmann, R. W., Solomon, S., Seidel, D. J., Lanzante, J., Klein, S., Ramaswamy, V., and Schwarzkopf, M. D.: A comparison of modelsimulated trends in stratospheric temperatures, Quart. J. R. Met. Soc., 129, 1565$1588,2003$.

Solomon, S., Portmann, R. W., Garcia, R. R., Thomason, L. W., Poole, L. R., and McCormick, M. P.: The role of aerosol variations in anthropogenic ozone depletion at northern midlatitudes, J. Geophys. Res., 101, 6713-6727, 1996.

Solomon, S.: Stratospheric ozone depletion: A review of concepts and history, Rev. Geophys., 37, 275-316, 1999.

Steil, B., Dameris, M., Brühl, C., Crutzen, P. J., Grewe, V., Ponater, M., and Sausen, R.: Development of a chemistry module for GCMs: first results of a multiannual integration, Ann. Geophys., 16, 205-228, 1998,

\section{SRef-ID: 1432-0576/ag/1998-16-205.}

Steil, B., Brühl, C., Manzini, E., Crutzen, P. J., Lelieveld, J., Rasch, P. J., Roeckner, E., and Krüger, K.: A new interactive chemistry climate model: 1. Present day climatology and interannual variability of the middle atmosphere using the model and 9 years of HALOE/UARS data, J. Geophys. Res., 108(D9), 4290, doi:10.1029/2002JD002971, 2003.

Steinbrecht, W., Claude, H., Köhler, U., and Hoinka, K. P.: Correlations between tropopause height and total ozone: Implications for long-term changes, J. Geophys. Res., 103, 19183-19192, 1998.
Steinbrecht, W., Hassler, B., Claude, H., Winkler, P., and Stolarski, R. S.: Global distribution of total ozone and lower stratospheric temperature variations, Atmos. Chem. Phys., 3, 14211438, 2003,

SRef-ID: 1680-7324/acp/2003-3-1421.

Steinbrecht, W., Claude, H., and Winkler, P.: Enhanced upper stratospheric ozone: Sign of recovery or solar cycle effect?, J. Geophys. Res., 109(D2), 2308, doi:10.1029/2003JD004284, 2004.

Stenke, A. and Grewe, V.: Simulation of stratospheric water vapour trends: impact on stratospheric chemistry, Atmos. Chem. Phys., 5, 1257-1272, 2005, SRef-ID: 1680-7324/acp/2005-5-1257.

Stolarski, R. S. and Hollandsworth-Frith, S.: Combined total ozone record from TOMS and SBUV instruments, http://code916.gsfc.nasa.gov/Data_services/merged/data/ toms_sbuv.v3.78-02.5x10.v7.txt, 2003.

Timmreck, C., Graf, H.-F., and Steil, B.: Aerosol chemistry interactions after the Mt. Pinatubo eruption, in: Volcanism and the Earth's Atmosphere, edited by: Robock, A. and Oppenheimer, C., Geophys. Monograph Series, 139, American Geophysical Union, Washington D.C., pp. 213-225, 2004.

Thompson, D. W. J. and Wallace, J. M.: Annular modes in the extratropical circulation. Part I: Month-to-month variability, J. Climate, 13, 1000-1016, 2000.

Tourpali, K., Schuurmans, C. J. E., van Dorland, R., Steil, B., and Brühl, C.: Stratospheric and tropospheric response to enhanced solar UV-radiation: A model study, Geophys. Res. Lett., 30(5), 1231, doi:10.1029/2002GL016650, 2003.

Tourpali, K., Schuurmans, C. J. E., van Dorland, R., Steil, B., Brühl, C., and Manzini, E.: Solar cycle modulation of the North Atlantic Oscillation in a Chemistry-Climate Model, Geophys. Res. Lett., 32(17), L17803, doi:10.1029/2005GL023509, 2005.

Williamson, D. L. and Rasch, P. J.: Two-dimensional semiLagrangian transport with shape preserving interpolation, Mon. Wea. Rev., 117, 102-129, 1989.

WMO (World Meteorological Organization): Scientific Assessment of Ozone Depletion: 2002, Global Ozone Research and Monitoring ProjectReport No. 47, 498 pp., Geneva, http://www.wmo.ch/ web/arep/ozone.html, 2003.

Yang, H. and Tung, K. K.: On the phase propagation of extra tropical Quasi-Biennial Oscillation in observational data, J. Geophys. Res., 100, 9091-9100, 1995.

Zerefos, C. S., Tourpali, K., Bojkov, B. R., Balis, D. S., Rognerund, B., and Isaksen, I. S. A.: Solar activity-total column ozone relationships: Observations and model studies with heterogeneous chemistry, J. Geophys. Res., 102, 1561-1569, 1997. 